5 Research Square
Preprints are preliminary reports that have not undergone peer review.

They should not be considered conclusive, used to inform clinical practice, or referenced by the media as validated information.

\title{
An Architecture Based on FDDC between any two ONUs for Optical Access Network
}

\section{Yifan Zhu}

Shanghai University SCIE: Shanghai University School of Communications and Information Engineering Chaoqin Gan ( $\nabla$ cqgan@shu.edu.cn )

Shanghai University https://orcid.org/0000-0001-8622-802X

\section{Wei Lin}

Shanghai University SCIE: Shanghai University School of Communications and Information Engineering

\section{Guiyu Gong}

Shanghai University SCIE: Shanghai University School of Communications and Information Engineering

\section{Research Article}

Keywords: Optical network unit, Full duplex direct communications, Expansion module, Three-level protections, Optical access network

Posted Date: March 1st, 2021

DOI: https://doi.org/10.21203/rs.3.rs-253652/v1

License: (c) (1) This work is licensed under a Creative Commons Attribution 4.0 International License. Read Full License 


\title{
An Architecture Based on FDDC between any two ONUs for Optical Access Network
}

\author{
Yifan Zhu, Chaoqin Gan*, Wei Lin, Guiyu Gong \\ Key laboratory of Specialty Fiber Optics and Optical Access Networks, Joint International Research \\ Laboratory of Specialty Fiber Optics and Advanced Communication, Shanghai University. \\ Shanghai 200444, China \\ "E-mail: cqgan@shu.edu.cn
}

\begin{abstract}
A novel architecture with full-duplex direct communications(FDDC) between any two ONUs for optical access network is proposed in this paper. By designing combination switch(CS) ingeniously, the architecture is finished to realize FDDC between any two ONUs in wavelength division multiplexing passive optical networks(WDM-PONs). By utilizing interconnected optical fibers between ONUs, the network has achieved threelevel protections(feeder optical fiber protection, distributed optical fiber protection and interconnected optical fiber protection). By constructing expansion module(EM), the network can be flexibly expanded and optimized, and the CapEx and OpEx of network can be greatly reduced. Finally, by the simulation and analysis, the effectiveness of the proposed architecture is demonstrated.
\end{abstract}

Keywords: Optical network unit; Full duplex direct communications; Expansion module; Three-level protections; Optical access network

\section{Introduction}

With the vigorous development of data centers, cloud computing, and 5G mobile communications ${ }^{[1]}$, higher requirements of non-blocking and efficient communications are proposed in optical access networks ${ }^{[2]}$. Direct communications between ONUs is an efficient approach to handle the above challenges ${ }^{[4]}$. So, the research on this project gradually becomes one of the hot projects of optical access network ${ }^{[5]}$.

To the existing network architectures of direct communications between ONUs, they are mainly divided into three types: star topology, ring topology and grid topology. At the beginning, researchers mainly focus on direct communications between ONUs in star topology and ring topology. As the advantages of grid topology in direct communication become more and more obvious, researchers gradually focus on grid topology. To direct communication between ONUs in star topology, Zhang et al. realize half-duplex communications between ONUs by forming the ONU into a loop and using the power distribution module ${ }^{[12]}$. To direct communications between ONUs in ring topology, Baria Dipikaben Manharbhai et al. achieve half-duplex communications between ONUs by setting the FBG on the $\mathrm{RN}^{[11]}$. To direct communications between ONUs in grid topology, Li et al. realize half-duplex communications between ONUs by setting expansion module(EM) at $\mathrm{RN}^{[9]}$. This paper will research full-duplex direct communications(FDDC) between ONUs in grid network. It will not only shorten the communication link, but also greatly reduce the probability of signal blocking. 


\section{Network structure and operation principle}

\subsection{Architecture configuration and wavelength scheme}

The multi-service optical access network with FDDC between any ONUs is shown in figure 1. It includes a $\mathrm{CO}$, a RN, $\mathrm{n}$ groups of ONUs. $\mathrm{CO}$ and $\mathrm{RN}$ are connected through two feeder fibers(FF). One is working fiber, the other is protection fiber. Each ONU group is connected to RN by distributed fiber (DF). Similarly, these DFs are divided into working fibers and protection fibers. In the same ONU group, adjacent ONUs can establish communication connections through interconnecting optical fibers. The network can support three types of signal transmission. These three signals are: uplink signal, downlink signal and FDDC signal.

CO includes $n * n$ optical transmitters (Tx), a multiplexer (MUX), a circulator, an erbium-doped fiber amplifier (EDFA), a coupler, a $1 * 2$ optical switch(OS), a demultiplexer (DEMUX), $\mathrm{n} * \mathrm{n}$ optical receivers (Rx) and an EM. Here, EM consists of EMa and EMb. EMa is composed of $n * m$ optical transceivers (TRx), an arrayed waveguide grating(AWG) and an EDFA. EMb in ONU includes $m$ ONUs. Tx sends the downstream signal, and Rx receives the upstream signal from the ONU. TRxs send/receive data at other transmission rates.

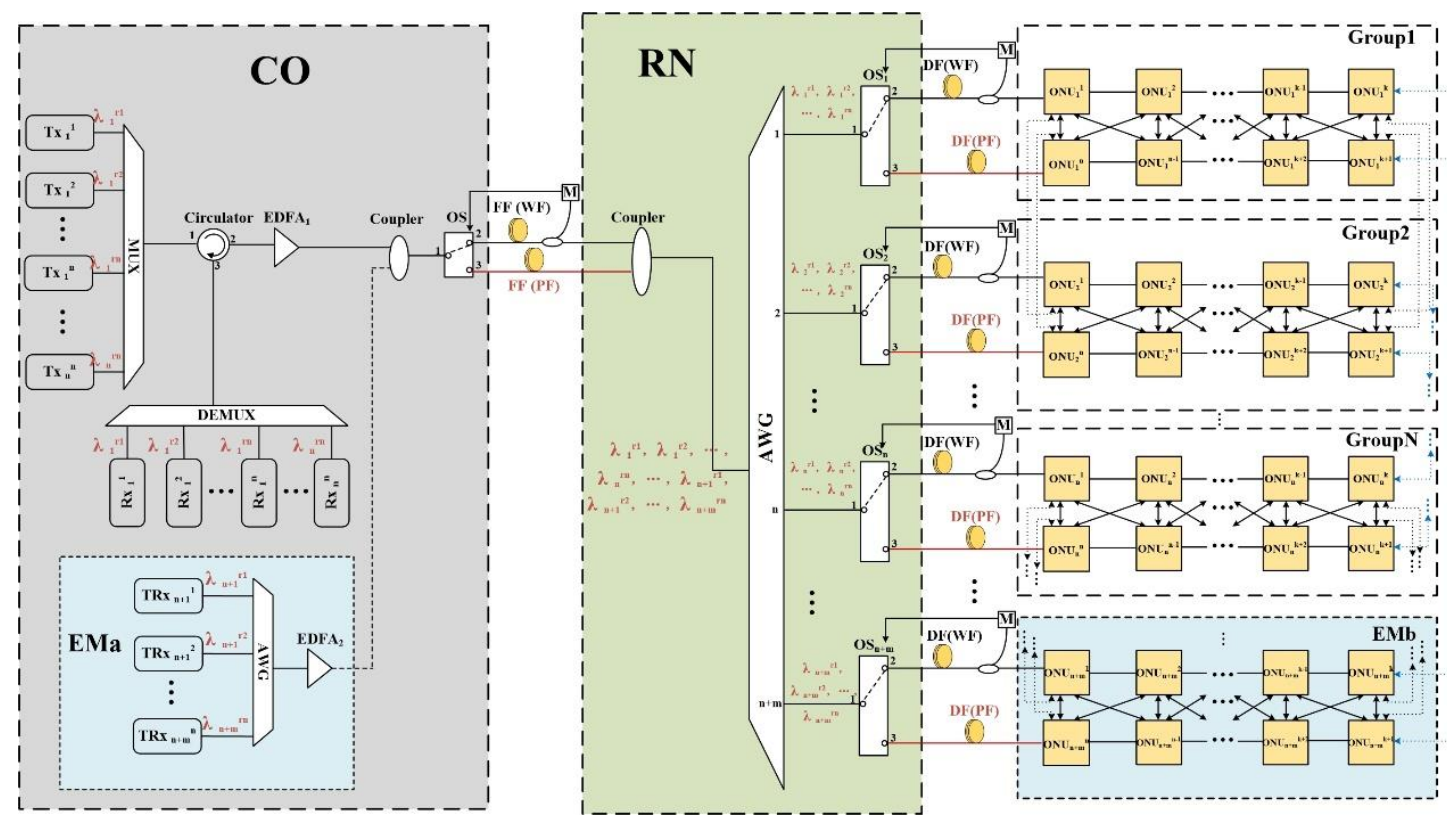

Figure 1. Network architecture with FDDC between ONUs

RN consists of a Coupler, an AWG and $n * m$ OSs. Each ONU group contains n ONUs. Here, define $\mathrm{ONU}_{\mathrm{j}}^{\mathrm{i}}$ as the $\mathrm{i}$-th $\mathrm{ONU}$ in the $\mathrm{j}$-th ONU group. The internal structures of all ONUs are the same. This design reduces the manufacturing cost and the maintenance cost of the ONU device. Here, take $\mathrm{ONU}_{1}{ }^{1}$ as an example to explain the internal structure of the ONU in detail. The internal structure of $\mathrm{ONU}_{1}{ }^{1}$ is shown in figure 2. It includes five coarse wavelength division multiplexers (CWDM), three OSs $\left(\mathrm{OS}_{1}, \mathrm{OS}_{2}, \mathrm{OS}_{3}\right)$, three optical circulators $\left(\mathrm{Cir}_{1}, \mathrm{Cir}_{2}, \mathrm{Cir}_{3}\right)$, a fiber bragg grating (FBG), six optical splitters, a coupler, a reflective semiconductor optical amplifier (RSOA), a wavelength filter (WF), an optical power monitor (M), a tunable optical transmitter (Tx) and two optical receivers $\left(\mathrm{Rx}_{1}\right.$ and $\left.\mathrm{Rx}_{2}\right)$. In the $\mathrm{ONU}$, all the connection states of the three optical switches $\left(\mathrm{OS}_{1}, \mathrm{OS}_{2}\right.$, and $\left.\mathrm{OS}_{3}\right)$ are shown in Table 1 . $\mathrm{Cir}_{1}$ and $\mathrm{Cir}_{3}$ are closed optical circulators. RSOA in ONU erases the downstream signal information from $\mathrm{CO}$ and re-modulates it into the upstream signal. The tunable $\mathrm{Tx}$ in the ONU is used to send FDDC signals between ONUs. In addition, $\mathrm{Rx}_{1}$ 
receives the downstream signal from $\mathrm{CO}$, and $\mathrm{Rx}_{2}$ receives the FDDC signals between ONUs. As the above analysis shows, this design enables the network to support the transmission of uplink signals, downlink signals and FDDC signals.

Table 1. All connection status of $\mathrm{OS}_{1}, \mathrm{OS}_{2}, \mathrm{OS}_{3}$

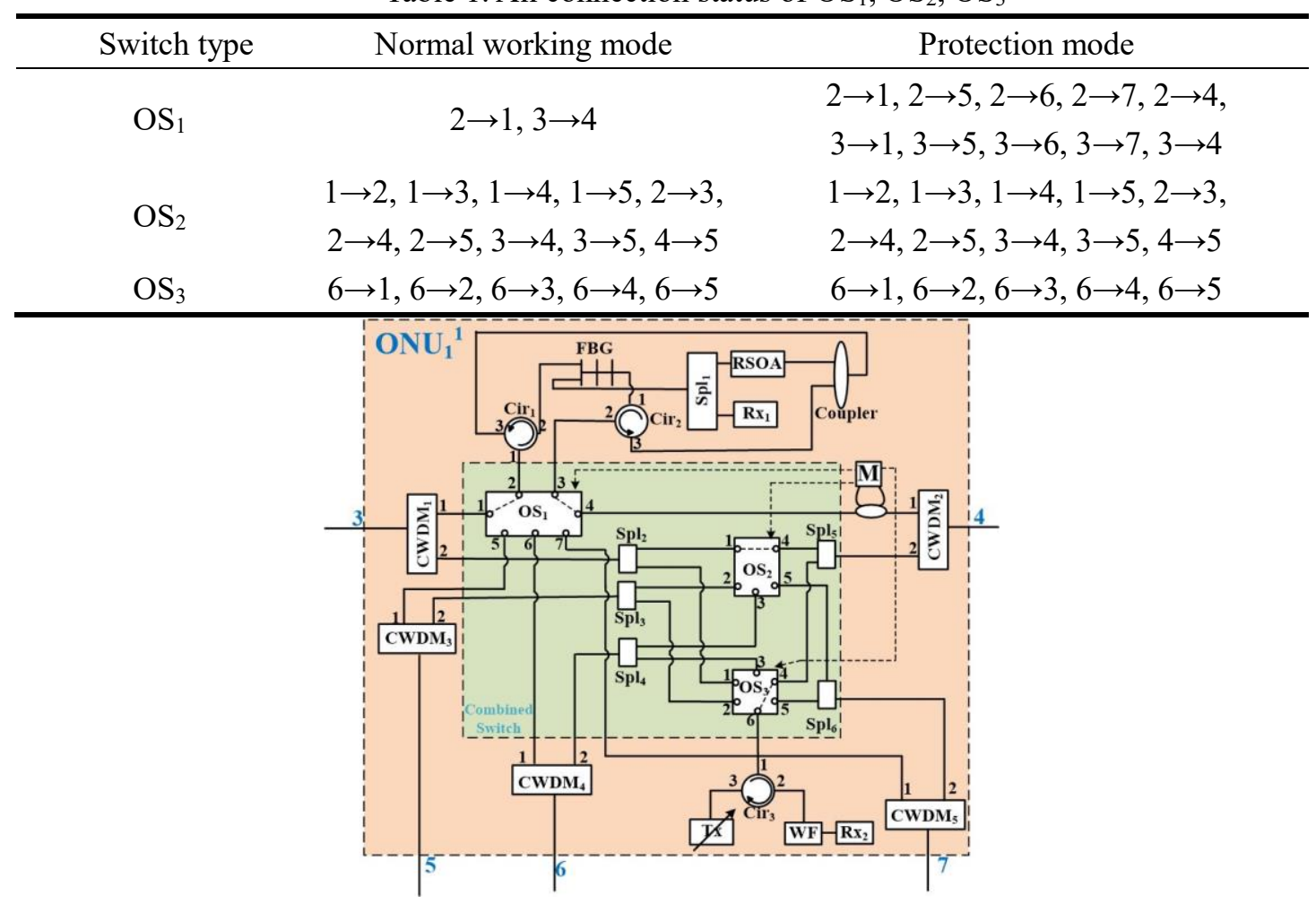

Figure 2. The structure of ONU

Based on the WDM technology, the specific wavelength settings are shown in Figure 3. The network allocates specific wavelengths for each ONU to transmit uplink signal, downlink signal, and FDDC signal. The wavelengths in the red band are used for uplink and downlink signals, and the wavelengths in the blue band are used for FDDC signals between ONUs. $\lambda_{j}^{\text {ri }}$ is the communication signal wavelength working in the red band and allocated to $\mathrm{ONU}_{\mathrm{j}}^{\mathrm{i}} . \lambda_{\mathrm{j}}^{\mathrm{bi}}$ is the communication signal wavelength working in the blue band and allocated to $\mathrm{ONU}_{\mathrm{j}}^{\mathrm{i}}$. Here, take $\mathrm{ONU}_{2}{ }^{3}$ as an example. To downlink communication, the downlink signal allocated to $\mathrm{ONU}_{2}{ }^{3}$ is carried on the wavelength $\lambda_{2}{ }^{\mathrm{r} 3}$. To uplink communication, after the RSOA receives the wavelength $\lambda_{2}{ }^{r 3}$, then the downstream signal carried on the wavelength is erased. After that, the upstream signal is modulated to the wavelength $\lambda_{2}{ }^{\mathrm{r} 3}$ and transmitted back to the CO. To FDDC, if one ONU needs to full-duplex-and-directly communicate with the $\mathrm{ONU}_{2}{ }^{3}$, the $\mathrm{ONU}$ should send a direct communication signal carried on $\lambda_{2}{ }^{\mathrm{b} 3}$ to the $\mathrm{ONU}_{2}{ }^{3}$.

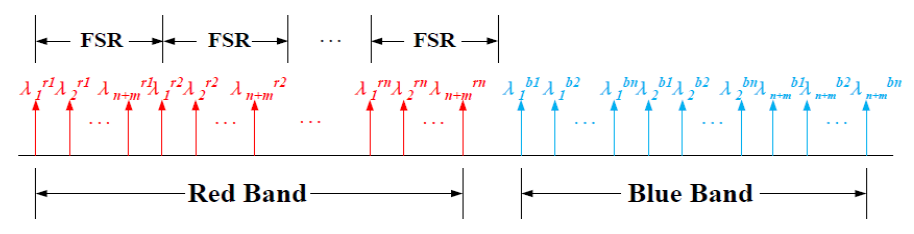

Figure 3. Wavelength allocation scheme 


\subsection{Normal working mode}

\subsubsection{Downlink signal transmission principle}

In the normal working mode, as shown in Figure 1, the $n^{*} n$ transmitters in CO transmit downlink signals. The modulation mode of the downstream signal is differential phase shift keying (DPSK). From $\mathrm{CO}$ to FF, the transmission path of the downlink signal is: MUX $\rightarrow$ port 1 of the Circulator $\rightarrow$ port 2 of the Circulator $\rightarrow$ EDFA $_{1} \rightarrow$ Coupler $\rightarrow$ port 1 of OS $\rightarrow$ port 2 of OS. All the downlink signals reach $\mathrm{RN}$ through the working fiber.

In RN, the downlink signals reach the AWG through the Coupler. According to Figure 3, the downstream signals in the same ONU group will be output from the same output port of the AWG. Here, take Group1 as an example to explain signal transmission principle. The transmission path of the downlink signal is: coupler $\rightarrow$ port 1 of AWG $\rightarrow$ port 1 of OS $1 \rightarrow$ port2 of OS $1 \rightarrow$ working fiber $\rightarrow$ $\mathrm{ONU}_{1}{ }^{1} \rightarrow \ldots \rightarrow \mathrm{ONU}_{1}{ }^{\mathrm{n}}$. The specific transmission path is shown in Figure 4. Take $\mathrm{ONU}_{1}{ }^{1}$ as an example to explain signal transmission principle in each ONU. The transmission path of the downlink signals is: $\mathrm{CWDM} 1 \rightarrow$ port 1 of $\mathrm{OS}_{1} \rightarrow$ port 2 of $\mathrm{OS}_{1} \rightarrow$ port 1 of $\mathrm{Cir}_{1} \rightarrow$ port 2 of $\mathrm{Cir}_{1} \rightarrow$ $\mathrm{FBG} \rightarrow \mathrm{spl1} \rightarrow \mathrm{Rx}_{1}$. Here, all CWDMs in the ONU are used to separate red band and blue band signals. The red band signal will be output from port 1 of the CWDM, and the blue band signal will be output from port 2. The connection status of the switch $\mathrm{OS}_{1}$ in ONU under normal working mode is shown in Table 2. FBG reflects the downstream signal $\lambda_{1}{ }^{r 1}$ to the splitter ${ }_{1}$. Downlink signals that are not reflected by FBG are input from port 1 of $\mathrm{Cir}_{2}$. Then, the transmission path of the signals is: port 1 of $\mathrm{Cir}_{2} \rightarrow$ port 2 of $\mathrm{Cir}_{2} \rightarrow$ port 3 of $\mathrm{OS}_{1} \rightarrow$ port 4 of $\mathrm{OS}_{1} \rightarrow \mathrm{CWDM}_{2} \rightarrow$ interconnected fiber between $\mathrm{ONU}_{1}{ }^{1}$ and $\mathrm{ONU}_{1}{ }^{2} \rightarrow \mathrm{ONU}_{1}{ }^{2}$. Then, by using the same transmission principle, the signal is transmitted to $\mathrm{ONU}_{1}{ }^{\mathrm{n}}$ in sequence. Now, the network has completed the transmission of downlink signals.

Table 2. The connection status of $\mathrm{OS}_{1}$ in $\mathrm{ONU}$ under normal working mode

\begin{tabular}{cccccccc}
\hline $0 \mathrm{NU} 1^{1}$ & $\mathrm{ONU}^{2}$ & $\cdots$ & $\mathrm{ONU}^{\mathrm{k}}$ & $\mathrm{ONU}^{\mathrm{k}+1}$ & $\cdots$ & $\mathrm{ONU}^{\mathrm{n}-1}$ & $\mathrm{ONU}^{\mathrm{n}}$ \\
\hline $2 \rightarrow 1$ & $2 \rightarrow 1$ & $\ldots$ & $2 \rightarrow 1$ & $2 \rightarrow 4$ & $\ldots$ & $2 \rightarrow 4$ & $2 \rightarrow 4$ \\
$3 \rightarrow 4$ & $3 \rightarrow 4$ & $\ldots$ & $3 \rightarrow 4$ & $3 \rightarrow 1$ & $\ldots$ & $3 \rightarrow 1$ & $3 \rightarrow 1$ \\
\hline
\end{tabular}




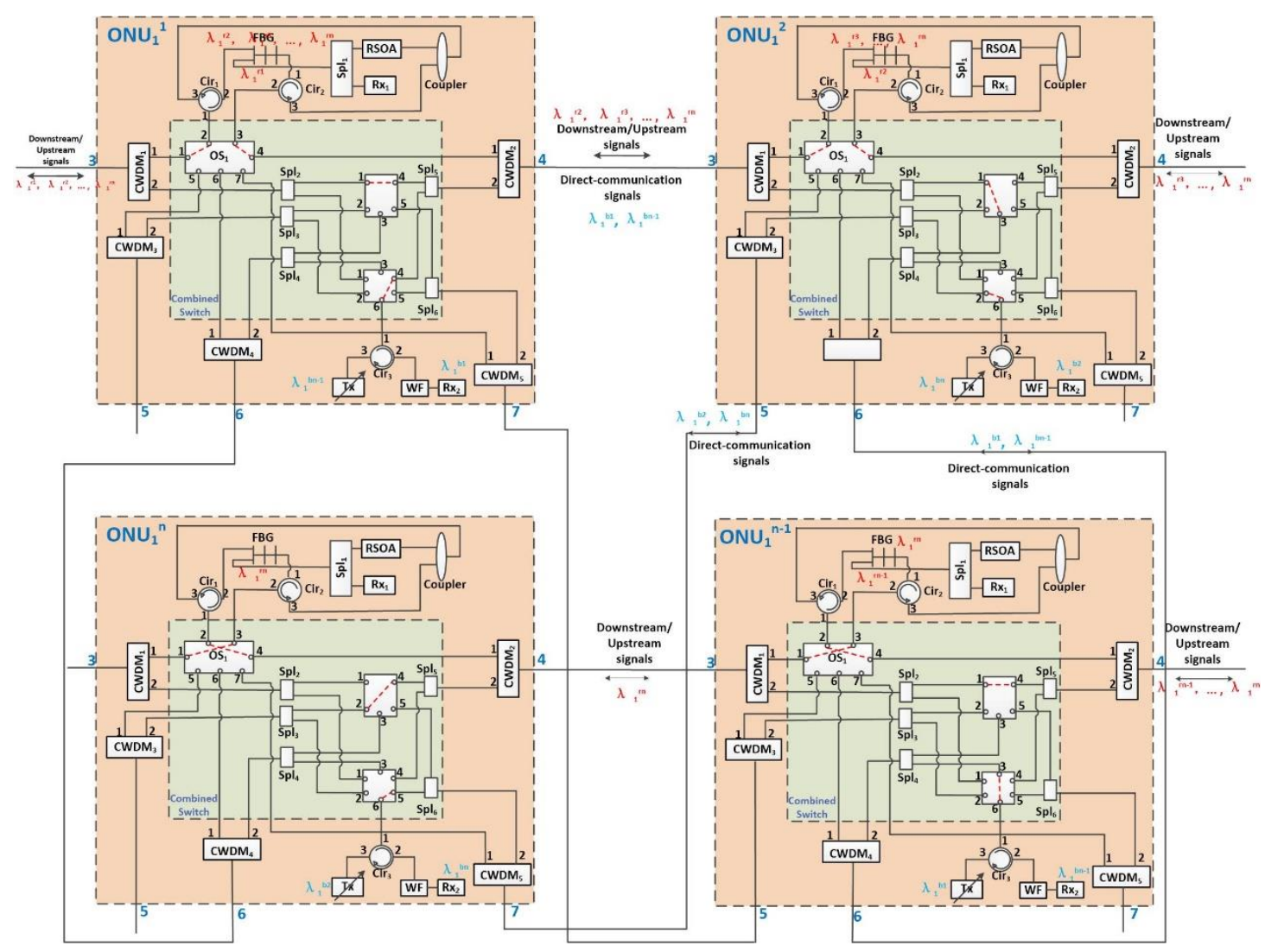

Figure 4. Normal working mode

\subsubsection{Uplink signal transmission principle}

In the normal working mode, take $\mathrm{ONU}_{1}{ }^{1}$ as an example to explain signal transmission principle in each ONU. The transmission path of the upstream signals from $\mathrm{ONU}_{1}{ }^{2}$ to $\mathrm{ONU}_{1}{ }^{1}$ is: CWDM $2 \rightarrow$ port 4 of OS $1 \rightarrow$ port 3 of OS $1 \rightarrow$ port 2 of $\mathrm{Cir} 2 \rightarrow$ port 3 of $\mathrm{Cir} 2 \rightarrow$ coupler. The upstream signal from RSOA and the upstream signals from port 3 of $\mathrm{Cir} 2$ are combined into port 3 of $\mathrm{Cir}_{1}$ by coupler. The transmission path of combined upstream signals is: coupler $\rightarrow$ port 3 of $\mathrm{Cir}_{1} \rightarrow$ port 1 of $\mathrm{Cir}_{1} \rightarrow$ port 2 of OS $1 \rightarrow$ port 2 of OS $1 \rightarrow$ port 1 of CWDM1. So, the uplink signals from port 1 of $\mathrm{CWDM}_{1}$ will reach the RN through DF. In RN, Group 1 's upstream signals from $\mathrm{OS}_{1}$ are multiplexed into Coupler by AWG. The multiplexed uplink signals from the Coupler are transmitted to CO through FF. In CO, the transmission path of uplink signals from OS to EMa is: OS $\rightarrow$ Coupler $\rightarrow \mathrm{EDFA}_{2} \rightarrow \mathrm{AWG} \rightarrow \mathrm{TRx}$. The transmission path of remaining uplink signals is: OS $\rightarrow$ Coupler $\rightarrow$ EDFA $_{1} \rightarrow$ port 2 of Circulator $\rightarrow$ port 3 of Circulator $\rightarrow$ DEMUX $\rightarrow$ Rx. Up to now, the network has completed the transmission of the uplink signals.

\subsubsection{Principle of FDDC between ONUs}

Here, modes of FDDC between ONUs contain: Mode 1(FDDC within the same ONU group) and Mode 2(FDDC between different ONU groups).

(1) The transmission principle of Mode 1

In fig.4, any two ONUs can full-duplex-and-directly communicate with each other. In normal working mode, when $\mathrm{ONU}_{1}{ }^{1}$ communicates with $\mathrm{ONU}_{1}{ }^{\mathrm{n}-1}$, Tx in $\mathrm{ONU}_{1}{ }^{1}$ transmits $\lambda_{1}{ }^{\mathrm{bn}-1}$. In $\mathrm{ONU}_{1}{ }^{1}$, the path of $\lambda_{1}{ }^{\text {bn- }-1}$ is: port 3 of $\mathrm{Cir}_{3} \rightarrow$ port 1 of $\mathrm{Cir}_{3} \rightarrow$ port 6 of $\mathrm{OS}_{3} \rightarrow$ port 5 of $\mathrm{OS}_{3} \rightarrow \mathrm{Spl}_{6} \rightarrow \mathrm{CWDM}_{5} \rightarrow$ interconnected fiber between $\mathrm{ONU}_{1}{ }^{1}$ and $\mathrm{ONU}_{1}{ }^{\mathrm{n}-1} \rightarrow \mathrm{ONU}_{1}{ }^{\mathrm{n}-1}$. In $\mathrm{ONU}_{1}{ }^{\mathrm{n}-1}$, the path of $\lambda_{1}{ }^{\text {bn-1 }}$ is: port 2 of $\mathrm{CWDM}_{3} \rightarrow \mathrm{Spl}_{3} \rightarrow$ port 2 of $\mathrm{OS}_{3} \rightarrow$ port 6 of $\mathrm{OS}_{2} \rightarrow$ port 1 of $\mathrm{Cir}_{3} \rightarrow$ port 2 of $\mathrm{Cir}_{3} \rightarrow \mathrm{WF} \rightarrow \mathrm{Rx}_{2}$. 
Similarly, communication signals can be transmitted through the link of $\mathrm{ONU}_{1}{ }^{\mathrm{n}-1} \rightarrow \mathrm{ONU}_{1}{ }^{1}$. Up to now, the network has completed the FDDC between $\mathrm{ONU}_{1}{ }^{1}$ and $\mathrm{ONU}_{1}{ }^{\mathrm{n}}{ }^{-1}$. For the FDDC between $\mathrm{ONU}_{1}{ }^{\mathrm{n}}$ and $\mathrm{ONU}_{1}{ }^{2}$, in the communication mode of $\mathrm{ONU}_{1}{ }^{\mathrm{n}} \rightarrow \mathrm{ONU}_{1}{ }^{2}$, Tx in $\mathrm{ONU}_{1}{ }^{\mathrm{n}}$ transmits $\lambda_{1}{ }^{\mathrm{b} 2}$. In $\mathrm{ONU}_{1}{ }^{\mathrm{n}}$, the path of $\lambda_{1}{ }^{\mathrm{b} 2}$ is: port 3 of $\mathrm{Cir}_{3} \rightarrow$ port 1 of $\mathrm{Cir}_{3} \rightarrow$ port 6 of $\mathrm{OS}_{3} \rightarrow$ port 5 of $\mathrm{OS}_{3} \rightarrow \mathrm{Spl}_{6} \rightarrow \mathrm{CWDM}_{5} \rightarrow$ interconnected fiber between $\mathrm{ONU}_{1}{ }^{\mathrm{n}}$ and $\mathrm{ONU}_{1}{ }^{2} \rightarrow \mathrm{ONU}_{1}{ }^{2}$. In $\mathrm{ONU}_{1}^{2}$, the path of $\lambda_{1}{ }^{\text {b2 }}$ is: port 2 of $\mathrm{CWDM}_{3} \rightarrow \mathrm{Spl}_{3} \rightarrow$ port 2 of $\mathrm{OS}_{3} \rightarrow$ port 6 of $\mathrm{OS}_{2} \rightarrow$ port 1 of $\mathrm{Cir}_{3} \rightarrow$ port 2 of $\mathrm{Cir}_{3} \rightarrow \mathrm{WF} \rightarrow \mathrm{Rx}_{2}$. Similarly, communication signals can be transmitted through the link of $\mathrm{ONU}_{1}{ }^{2} \rightarrow$ $\mathrm{ONU}_{1}{ }^{\mathrm{n}}$. Now, the network has completed the FDDC between $\mathrm{ONU}_{1}{ }^{\mathrm{n}}$ and $\mathrm{ONU}_{1}{ }^{2}$. It is worth noting that FDDC between $\mathrm{ONU}_{1}{ }^{1}$ and $\mathrm{ONU}_{1}{ }^{\mathrm{n}-1}$ and between $\mathrm{ONU}_{1}{ }^{\mathrm{n}}$ and $\mathrm{ONU}_{1}{ }^{2}$ can be realized simultaneously. More importantly, the FDDC between ONUs can select multiple different communication links to realize data transmission. As shown in Figure 5, when traffic congestion occurs in the established communication link, the network can choose alternative links.

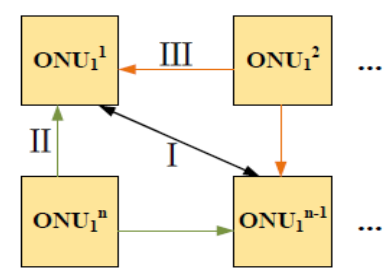

Figure 5. Flexible direct communication link

(2) The transmission principle of Mode 2

$\mathrm{ONU}_{1}{ }^{\mathrm{k}-1}$ in Group ${ }_{1}$ and $\mathrm{ONU}_{2}{ }^{\mathrm{k}}$ in Group 2 full-duplex-and-directly communicate with each other, as shown in fig. 6. When $\mathrm{ONU}_{1}{ }^{\mathrm{k}-1}$ communicates with $\mathrm{ONU}_{2}{ }^{\mathrm{k}}$, Tx in $\mathrm{ONU}_{1}^{\mathrm{k}-1}$ transmits $\lambda_{2}{ }^{\mathrm{bk}}$. In $\mathrm{ONU}_{1}{ }^{\mathrm{k}-1}$, the path of $\lambda_{2}{ }^{\mathrm{bk}}$ is: port 3 of $\mathrm{Cir}_{3} \rightarrow$ port 1 of $\mathrm{Cir}_{3} \rightarrow$ port 6 of $\mathrm{OS}_{3} \rightarrow$ port 4 of $\mathrm{OS}_{3} \rightarrow \mathrm{Spl}_{5} \rightarrow \mathrm{CWDM}_{2} \rightarrow$ interconnection fiber between $\mathrm{ONU}_{1}{ }^{\mathrm{k}-1}$ and $\mathrm{ONU}_{1}{ }^{\mathrm{k}} \rightarrow \mathrm{ONU}_{1}{ }^{\mathrm{k}}$. In $\mathrm{ONU}_{1}{ }^{\mathrm{k}}$, the path of $\lambda_{2}{ }^{\mathrm{bk}}$ is: $\mathrm{CWDM}_{1} \rightarrow \mathrm{Spl}_{2} \rightarrow$ port 1 of $\mathrm{OS}_{2} \rightarrow$ port 5 of $\mathrm{OS}_{2} \rightarrow \mathrm{Spl}_{6} \rightarrow \mathrm{CWDM}_{5} \rightarrow$ interconnection fiber between $\mathrm{ONU}_{1}{ }^{\mathrm{k}}$ and $\mathrm{ONU}_{2}{ }^{\mathrm{k}} \rightarrow \mathrm{ONU}_{2}{ }^{\mathrm{k}}$. In $\mathrm{ONU}_{2}{ }^{\mathrm{k}}$, the path of $\lambda_{2}{ }^{\mathrm{bk}}$ is: $\mathrm{CWDM}_{5} \rightarrow \mathrm{Spl}_{6} \rightarrow$ port 5 of $\mathrm{OS}_{3} \rightarrow$ port 6 of $\mathrm{OS}_{3} \rightarrow$ port 1 of $\mathrm{Cir}_{3} \rightarrow$ port 2 of $\mathrm{Cir}_{3} \rightarrow$ WF $\rightarrow \mathrm{Rx}_{2}$. Similarly, When $\mathrm{ONU}_{2}{ }^{\mathrm{k}}$ communicates with $\mathrm{ONU}_{1}{ }^{\mathrm{k}-1}$, the $\mathrm{Tx}$ of $\mathrm{ONU}_{2}{ }^{\mathrm{k}}$ transmits $\lambda_{1}{ }^{\mathrm{bk}-1}$ back to $\mathrm{ONU}_{1}{ }^{\mathrm{k}-1}$ through the link of $\mathrm{ONU}_{1}^{\mathrm{k}-1} \rightarrow \mathrm{ONU}_{2}^{\mathrm{k}}$. The signal is received by $\mathrm{Rx}_{2}$ in $\mathrm{ONU}_{1}^{\mathrm{k}-1}$. Up to now, the network has completed FDDC between $\mathrm{ONU}_{1}^{\mathrm{k}-1}$ and $\mathrm{ONU}_{2}{ }^{\mathrm{k}}$. It is worth noting that the communication of mode 2 and mode 1 do not interfere with each other. Similarly, the communication link of Mode 2 is also flexible. 


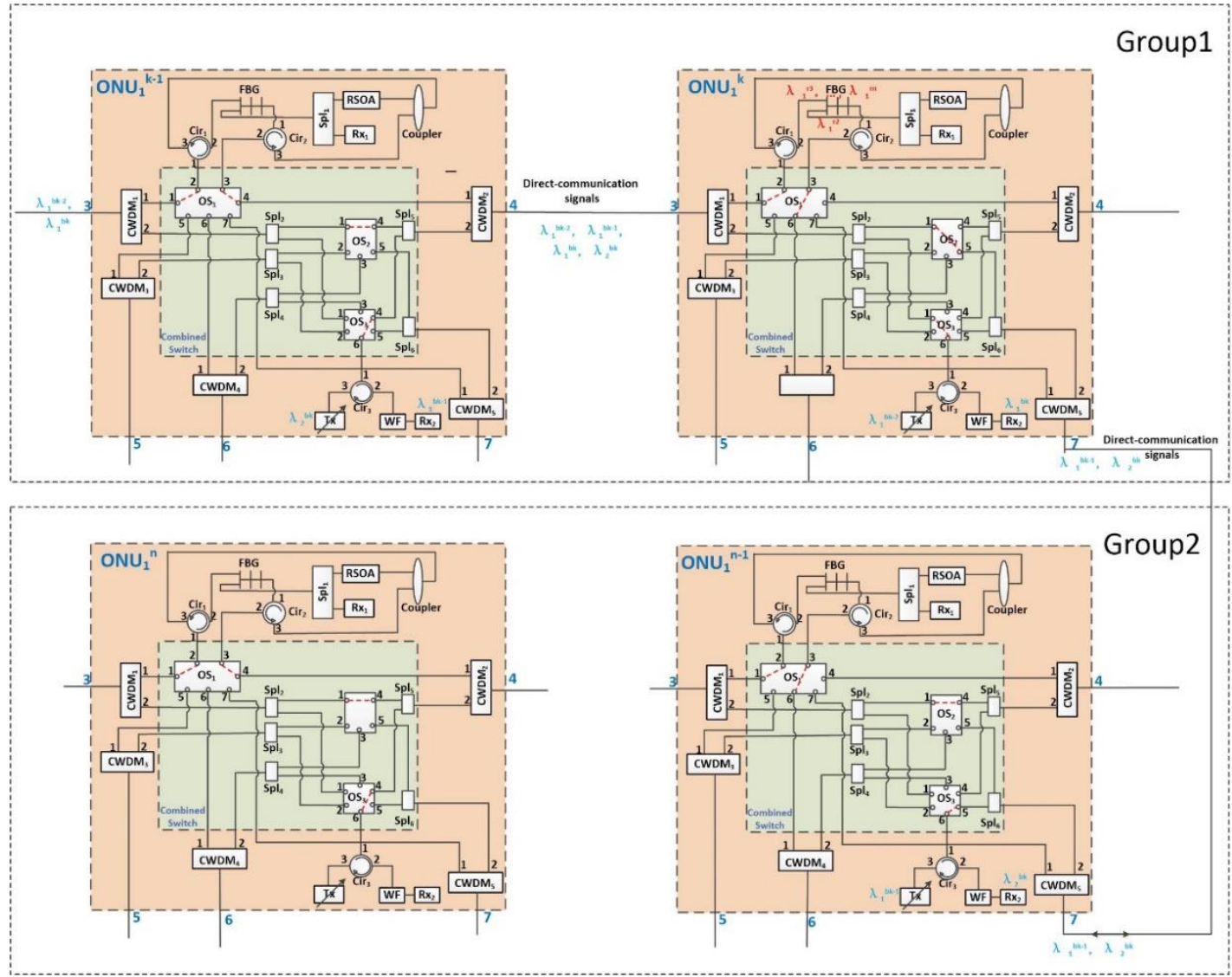

Figure 6. Communication between groups

\subsection{Protection Mode}

In view of different fiber failures, the network's protection modes can be divided into three types: Protection Mode 1, Protection Mode 2 and Protection Mode 3 (shown in Fig.7). In Fig.7, (1), (2) and (3) respectively represent feeder fiber failure, distribution fiber failure and interconnected fiber failure. The three types of protection modes will be respectively clarified as follows..

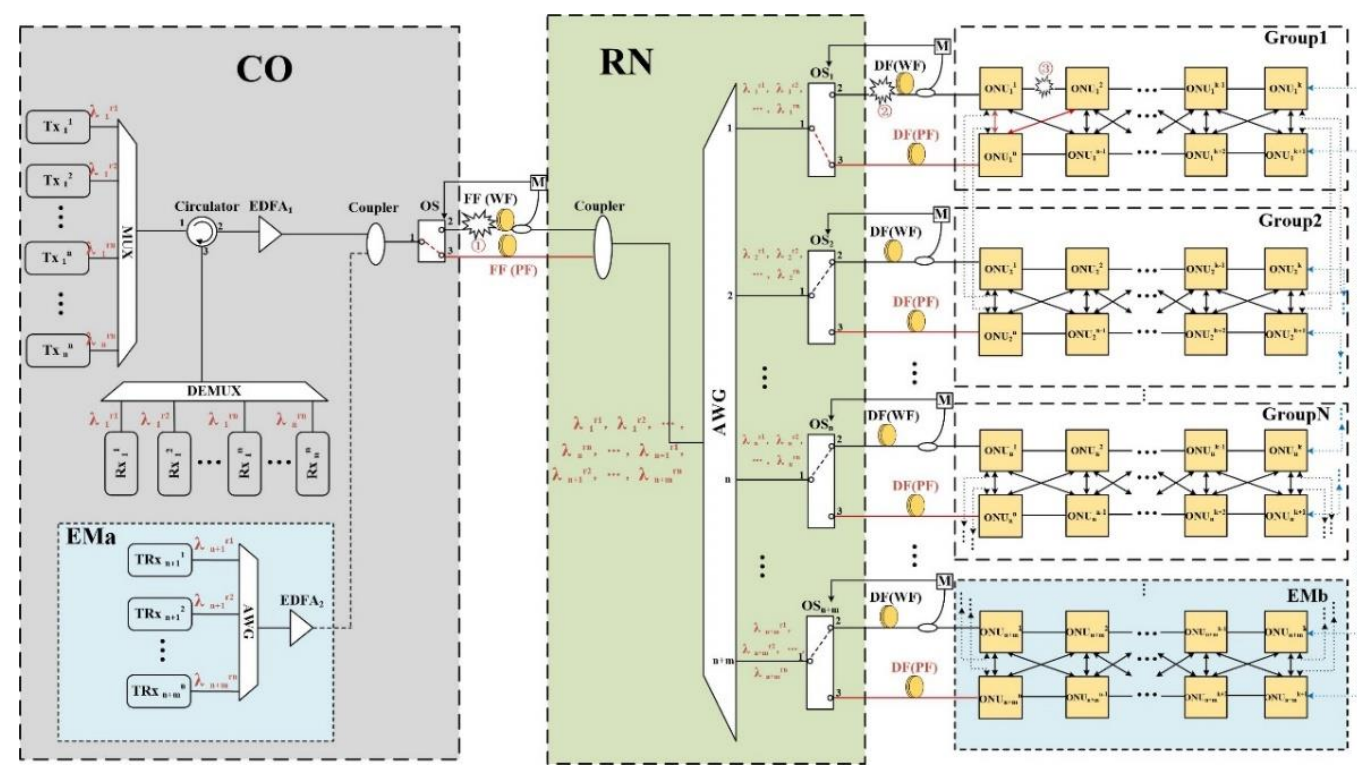

Figure 7. Protection Mode 1 


\subsubsection{Protection Mode 1}

In Fig.7, when (1) occurs, the optical power monitor cannot detect the downstream signal from the CO, and the network will switch to Protection Mode 1. In the Protection Mode 1, port 1 is switched to port 3 in OS of CO. So, all the downstream signals will enter the RN through the protection fiber. In the same way, all upstream signals from the ONUs will be also transmitted from the $\mathrm{RN}$ back to the $\mathrm{CO}$ through the protection fiber. Up to now, the communication signal resumes normal transmission. Namely, the network is protected.

\subsubsection{Protection Mode 2}

When (2) occurs(shown in Fig.8), the optical power monitor cannot detect the downlink signal from RN, the network will switch to Protection Mode 2. In Protection Mode 2, port 1 is connected to port 3 in $\mathrm{OS}_{1}$ of RN. The downstream signal interrupted by failure will resume transmission through the protection fiber of DF. At this time, port 2 is connected to port 6 in $\mathrm{OS}_{1}$ of $\mathrm{ONU}_{1}{ }^{1}$, port 2 is connected to port 1 in $\mathrm{OS}_{1}$ of $\mathrm{ONU}_{1}^{\mathrm{n}}$, and port 3 is connected to port 6 in $\mathrm{OS}_{1}$ of $\mathrm{ONU}_{1}{ }^{\mathrm{n}}$. The downlink signal transmission link changes from $\mathrm{ONU}_{1}{ }^{1} \rightarrow \mathrm{ONU}_{1}{ }^{2} \rightarrow \ldots \rightarrow \mathrm{ONU}_{1}{ }^{\mathrm{n}}$ to $\mathrm{ONU}_{1}{ }^{\mathrm{n}} \rightarrow$ $\mathrm{ONU}_{1}{ }^{1} \rightarrow \ldots \rightarrow \mathrm{ONU}_{1}{ }^{\mathrm{n}-1}$. The signal resumes communication and the network is protected. It is worth noting that the optical fiber failure in mode 2 does not affect the direct communication service at ONU.

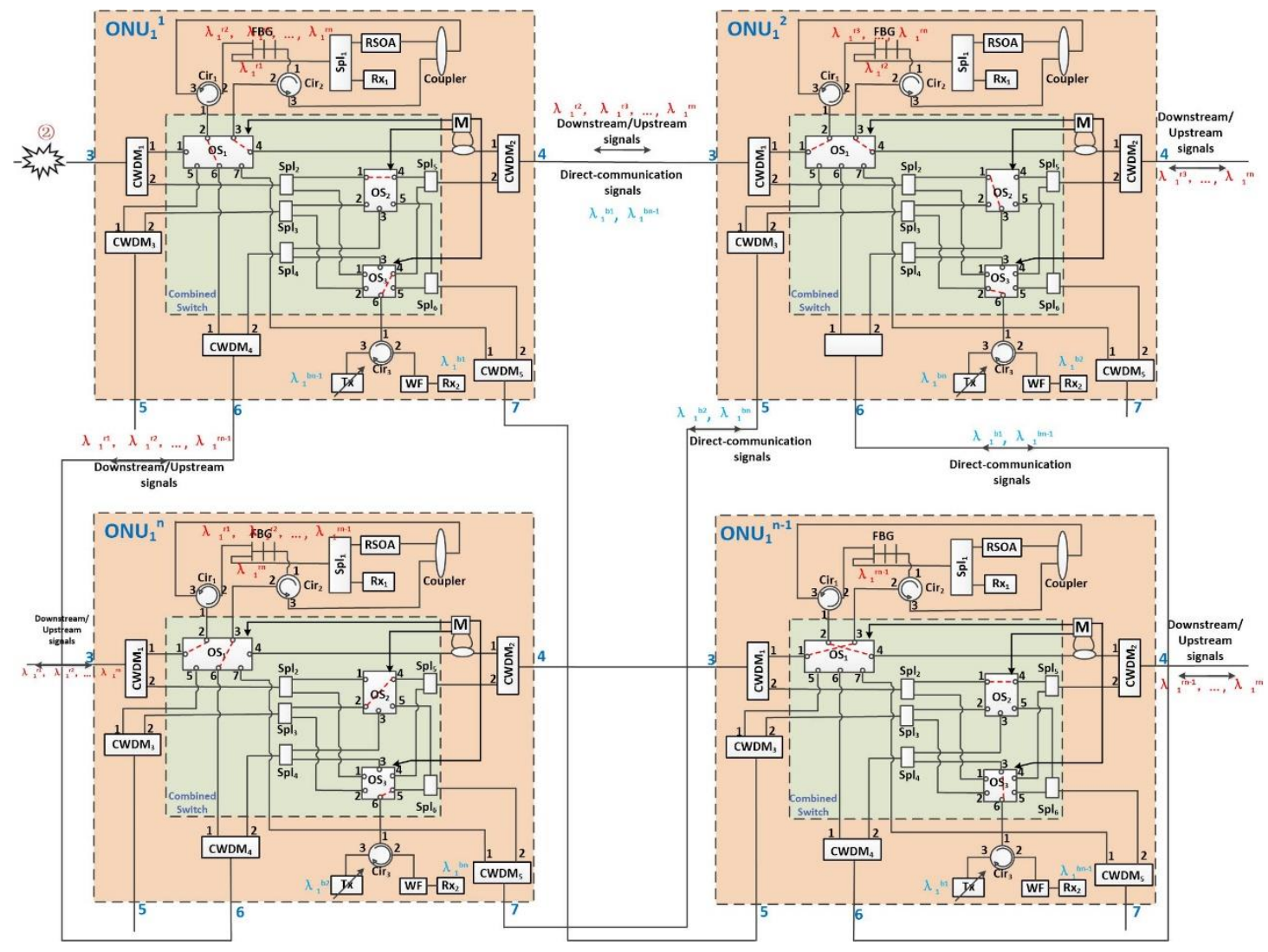

Figure 8. Protection Mode 2

\subsubsection{Protection Mode 3}

When the interconnection fiber between ONUs fails, the network will switch to Protection Mode 3. Taking (3) as an example, the optical power monitor in $\mathrm{ONU}_{1}{ }^{1}$ cannot detect the direct 
communication signal from $\mathrm{ONU}_{1}^{2}$, and the optical power monitor of $\mathrm{ONU}_{1}{ }^{2}$ cannot detect the direct communication signal from $\mathrm{ONU}_{1}{ }^{1}$. Then, $\mathrm{OSs}$ in $\mathrm{ONU}_{1}{ }^{1}$ and $\mathrm{ONU}_{1}{ }^{2}$ change the connection state. Port 3 is connected to port 6 in $\mathrm{OS}_{1}$ of $\mathrm{ONU}_{1}{ }^{1}$ (shown in Fig.9), and port 6 is connected to port 3 in $\mathrm{OS}_{3}$. In $\mathrm{OS}_{1}$ of $\mathrm{ONU}_{1}^{\mathrm{n}}$, port 2 is connected to port 6 , port 3 is connected to port 7. Port 3 is connected to port 5 in $\mathrm{OS}_{2}$ of $\mathrm{ONU}_{1}{ }^{\mathrm{n}}$. At the same time, port 2 is connected to port 3 in $\mathrm{OS}_{1}$ of $\mathrm{ONU}_{1}{ }^{2}$, and port 6 is connected to port 2 in $\mathrm{OS}_{3}$ of $\mathrm{ONU}_{1}^{2}$. The transmission link of the downstream signal becomes: $\mathrm{ONU}_{1}{ }^{1} \rightarrow \mathrm{ONU}_{1}{ }^{\mathrm{n}} \rightarrow \mathrm{ONU}_{1}{ }^{2} \rightarrow \ldots \rightarrow \mathrm{ONU}_{1}{ }^{\mathrm{n}-1}$. The transmission link of the FDDC between $\mathrm{ONU}_{1}{ }^{1}$ and $\mathrm{ONU}_{1}{ }^{2}$ changes from $\mathrm{ONU}_{1}{ }^{1} \rightarrow \mathrm{ONU}_{1}{ }^{2}, \mathrm{ONU}_{1}{ }^{2} \rightarrow \mathrm{ONU}_{1}{ }^{1}$ to $\mathrm{ONU}_{1}{ }^{1} \rightarrow \mathrm{ONU}_{1}{ }^{\mathrm{n}} \rightarrow \mathrm{ONU}_{1}{ }^{2}, \mathrm{ONU}_{1}{ }^{2} \rightarrow$ $\mathrm{ONU}_{1}{ }^{\mathrm{n}} \rightarrow \mathrm{ONU}_{1}{ }^{1}$. So, network communication is restored. The network can also realize multiprotection of interconnecting optical fibers by switching optical switches. FDDC between ONUs have different transmission links. So, Protection Mode 3 is flexible. Operators can choose the appropriate protection link according to actual needs.

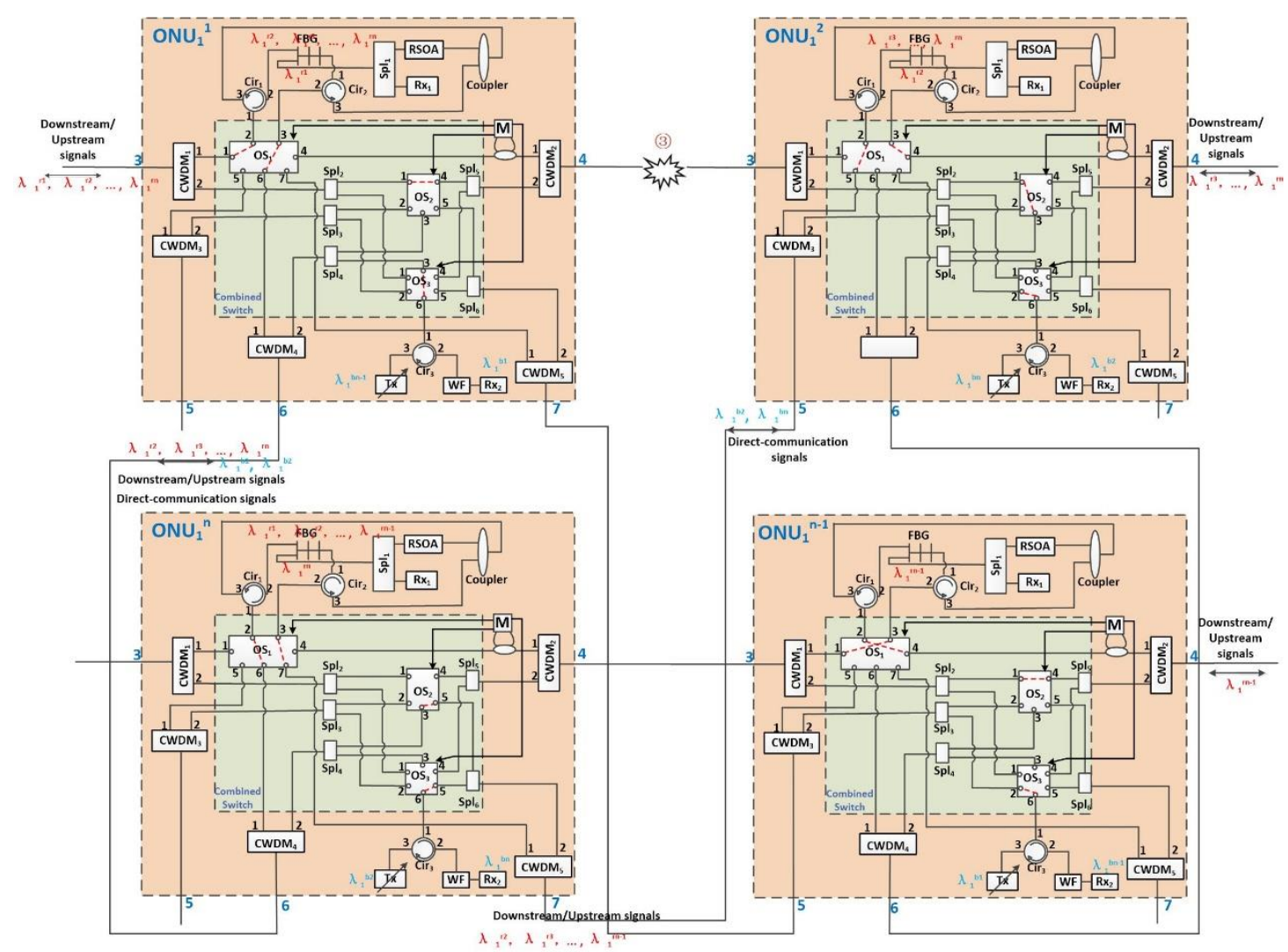

Figure 9. Protection Mode 3

\section{Network performance analysis}

\subsection{Power budget and network scale}

To describe clearly, define the maximum power loss of the signal as $\mathrm{L}$, the power margin of the network as LM and the power of the transmitter as PT. Define the sensitivity of the receiver as PR, the gain of EDFA as G, the number of ONUs supported by each ONU group as n. The lengths of feeder fiber between $\mathrm{CO}$ and $\mathrm{RN}$, distributed fiber between $\mathrm{RN}$ and $\mathrm{ONU}$ and interconnecting fiber between ONUs are $\mathrm{d} 1, \mathrm{~d} 2, \mathrm{~d} 3$ respectively. In addition, define the power losses of the optical signals at $\mathrm{CO}, \mathrm{RN}$ and $\mathrm{ONU}$ as $\mathrm{L}_{\mathrm{CO}}, \mathrm{L}_{\mathrm{RN}}$ and $\mathrm{L}_{\mathrm{ONU}}$ respectively. The power losses of the optical signals in 
the links between $\mathrm{CO}$ and $\mathrm{RN}, \mathrm{RN}$ and $\mathrm{ONU}$ are $\mathrm{L}_{\mathrm{CO}-\mathrm{RN}}$ and $\mathrm{L}_{\mathrm{RN}-\mathrm{ONU}}$ respectively. Insertion loss value of optical device related to the analysis process is shown in Table 3.

Table 3. Insertion loss value of optical device

\begin{tabular}{cccc}
\hline Component & Symbol & Insertion Loss (dB) & References \\
\hline MUX & $\mathrm{L}_{\mathrm{MUX}}$ & 3 & {$[2]$} \\
Circulator & $\mathrm{L}_{\mathrm{Cir}}$ & 0.5 & {$[2]$} \\
Coupler & $\mathrm{L}_{\mathrm{Cpl}}$ & 0.5 & {$[3]$} \\
Optical Switch & $\mathrm{L}_{\mathrm{OS}}$ & 0.5 & {$[2]$} \\
CWDM & $\mathrm{L}_{\mathrm{CWDM}}$ & 0.5 & {$[4]$} \\
FBG & $\mathrm{L}_{\mathrm{FBG}}$ & 3.5 & {$[5]$} \\
AWG & $\mathrm{L}_{\mathrm{AWG}}$ & 3 & {$[2]$} \\
Splitter & $\mathrm{L}_{\mathrm{Spl}}$ & 3 & {$[2]$} \\
Fiber & $\alpha \mathrm{F}$ & $0.2 \mathrm{~dB} / \mathrm{km}$ & {$[2]$} \\
\hline
\end{tabular}

According to Section 2, the downstream signal received by the last ONU in each ONU group suffers the greatest power loss. So, $\mathrm{L}$ can be expressed as:

$$
L=L_{C O}+L_{C O-R N}+L_{R N}+L_{R N-O N U}+L_{O N U}
$$

In Eq.(1), $\mathrm{L}_{\mathrm{CO}}, \mathrm{L}_{\mathrm{CO}-\mathrm{RN}}, \mathrm{L}_{\mathrm{RN}}, \mathrm{L}_{\mathrm{RN}-\mathrm{ONU}}$ and $\mathrm{L}_{\mathrm{ONU}}$ are given:

$$
\begin{gathered}
L_{C O}=L_{M U X}+L_{C i r}+L_{C p l}+L_{O S} \\
L_{C O-R N}=d_{1} \times \alpha_{F} \\
L_{R N}=L_{C p l}+L_{A W G}+L_{O S} \\
L_{R N-O N U}=d_{2} \times \alpha_{F} \\
L_{O N U}=\left(2 L_{C W D M}+2 L_{C i r}+2 L_{O S}+L_{F B G}+d_{3} \times \alpha_{F}\right) \cdot \\
(\mathrm{n}-1)+L_{C W D M}+L_{C i r}+L_{O S}+L_{F B G}+L_{S p l}
\end{gathered}
$$

Suppose $\mathrm{d} 1=10 \mathrm{~km}, \mathrm{~d} 2=2 \mathrm{~km}$, and $\mathrm{d} 3=0.5 \mathrm{~km}$. Substituting them into the above equations respectively, and then according to the specific values in Table 3, $\mathrm{L}$ can be gotten:

$$
L=6.6 n+12.3
$$

The maximum power loss $\mathrm{L}$ satisfies the following inequality:

$$
P_{T}+G-L-L_{M} \geq P_{R}
$$

Assume $\mathrm{LM}=5 \mathrm{~dB}$ and $\mathrm{PR}=-30 \mathrm{dBm}$, inequality can be gotten:

$$
n \leq\left(P_{T}+G+12.7\right)
$$

When $P_{\mathrm{T}}$ is set to $0 \mathrm{dBm}, 5 \mathrm{dBm}$ and $10 \mathrm{dBm}$, the relationship between $\mathrm{G}$ and $\mathrm{n}$ is shown in Fig.10. Obviously, $\mathrm{n}$ increases linearly with $\mathrm{G}$. 


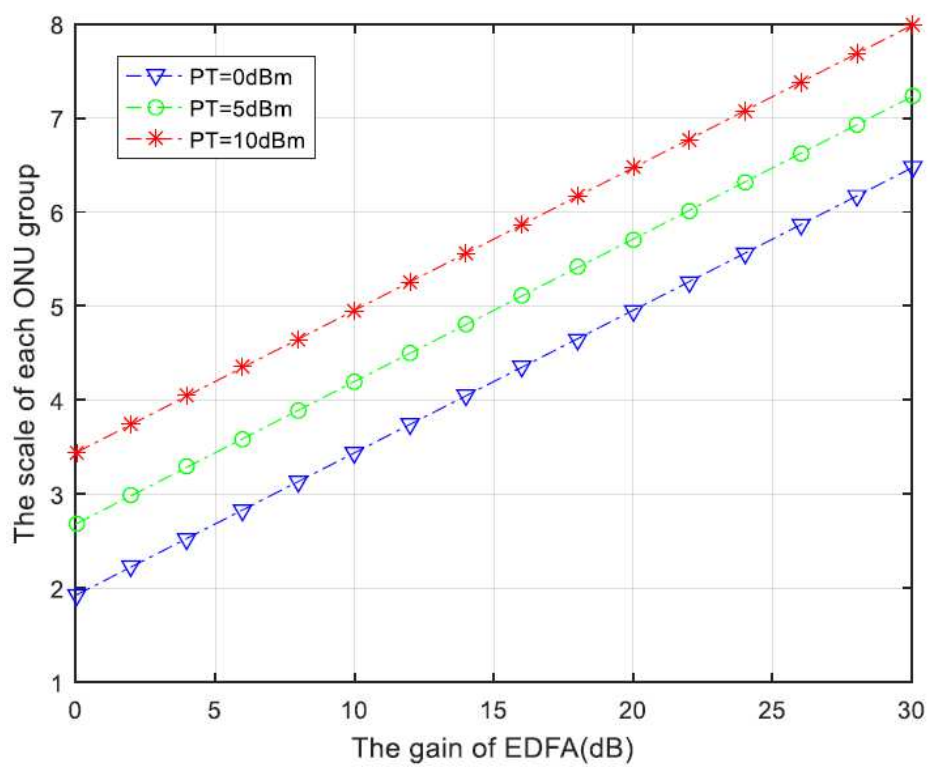

Figure 10. The relationship between $\mathrm{G}$ and $\mathrm{n}$ when $\mathrm{P}_{\mathrm{T}}$ is a fixed value

In addition, the relationship among $\mathrm{P}_{\mathrm{T}}, \mathrm{G}$ and $\mathrm{n}$ is shown in Fig.11. Obviously, along the G-axis, when $\mathrm{G}$ is constant, $\mathrm{n}$ increases as $\mathrm{P}_{\mathrm{T}}$ increases. Along the $\mathrm{P}_{\mathrm{T}}$-axis, when $\mathrm{P}_{\mathrm{T}}$ is constant, $\mathrm{n}$ increases as $G$ increases. Fig. 11 shows: $n$ is 6.47 when $P_{T}$ is $0 \mathrm{dBm}$ and $\mathrm{G}$ is $30 \mathrm{~dB}$. In practice, $n$ should be an integer and be rounded down. When $P_{T}$ is $0 \mathrm{dBm}$ and $\mathrm{G}$ is $30 \mathrm{~dB}$, The maximum number of $\mathrm{n}$ is 6. The maximum number of output ports supported by an AWG is 128 . So, the maximum number of ONUs supported by network is 768 .

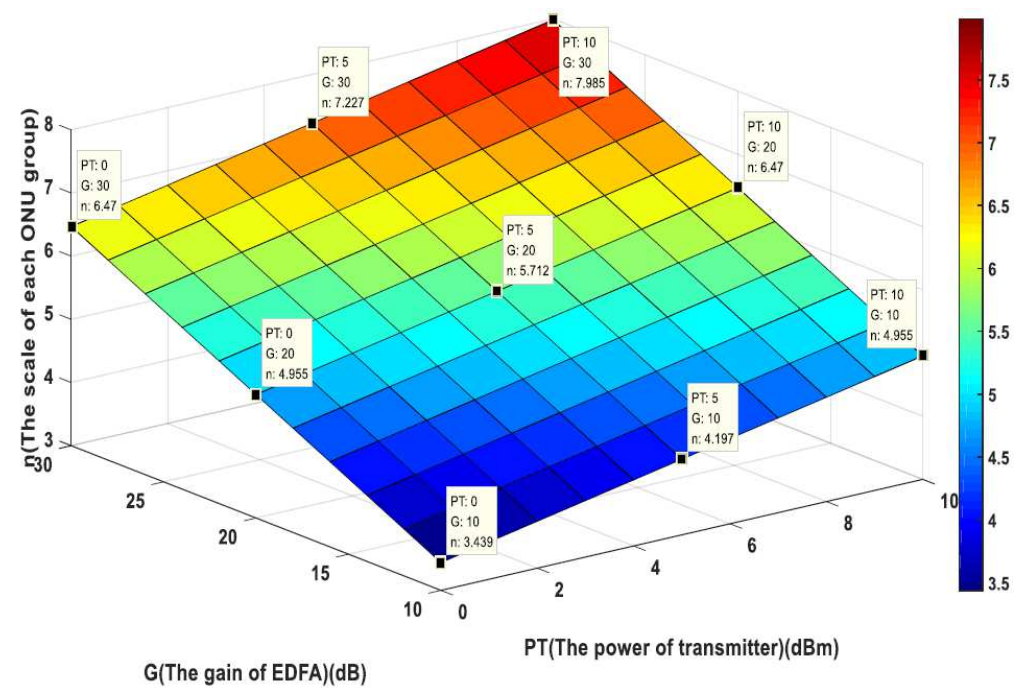

Figure 11. The relationship between $\mathrm{P}_{\mathrm{T}}, \mathrm{G}$ and $\mathrm{n}$

\subsection{Network reliability}

According to Fig.1, the downlink communication signal transmission link received by the last ONU in each ONU group is the longest. Here, the longest link will be taken as an example to analyze the reliability of network. The unreliability values of related optical devices are shown in Table 4. Define the reliability and the unreliability of the network as A and U respectively. The relationship between two parameters are shown: 


$$
A+U=1
$$

Define the unreliability of the $\mathrm{CO}$ as $\mathrm{U}_{\mathrm{CO}}$, the unreliability between $\mathrm{CO}$ and $\mathrm{RN}$ as $\mathrm{U}_{\mathrm{CO}-\mathrm{RN}}$, the unreliability between $\mathrm{RN}$ as $\mathrm{U}_{\mathrm{RN}}$, the unreliability between $\mathrm{RN}$ and $\mathrm{ONU}$ as $\mathrm{U}_{\mathrm{RN}-\mathrm{ONU}}$, and the unreliability of ONU as $\mathrm{U}_{\mathrm{ONU}}$. Then, the network unreliability $\mathrm{U}$ can be expressed as:

$$
U=U_{C O}+U_{C O-R N}+U_{R N}+U_{R N-O N U}+U_{O N U}
$$

In $\mathrm{Eq}(11), \mathrm{U}_{\mathrm{CO}}, \mathrm{U}_{\mathrm{CO}-\mathrm{RN}}, \mathrm{U}_{\mathrm{RN}}, \mathrm{U}_{\mathrm{RN}-\mathrm{ONU}}$ and $\mathrm{UONU}$ are respectively given by:

$$
\begin{gathered}
U_{C O}=U_{O L T}+U_{C i r}+U_{E D F A}+U_{C p l}+U_{O S} \\
U_{C O-R N}=(\mathrm{d} 1 \cdot \mathrm{UF})^{2} \\
U_{R N}=U_{C p l}+U_{A W G}+U_{O S} \\
U_{R N-O N U}=\left(2 U_{A W G}+2 U_{O S}+2 U_{C i r}+U_{F B G}+d_{3} \cdot \mathrm{U}_{F}\right) \\
\cdot(\mathrm{n}-1) \cdot d_{2} \cdot \mathrm{U}_{F}+(\mathrm{d} 2 \cdot \mathrm{UF})^{2} \\
U_{O N U}=U_{C W D M}+U_{O S}+U_{C i r}+U_{F B G}+U_{S p l}+U_{O L T}
\end{gathered}
$$

Substitute the data in Table 4 to $\operatorname{Eq}(11)$, A can be calculated:

$$
A \approx 1-2.2444 \times 10^{-5}
$$

Table 4 Unreliability values of optical devices

\begin{tabular}{cccc}
\hline Component & Symbol & Unreliability (Failure/109h) & References \\
\hline OLT & $\mathrm{U}_{\mathrm{OLT}}$ & $5.12 \times 10^{-7}$ & {$[2]$} \\
Coupler & $\mathrm{U}_{\mathrm{Cpl}}$ & $4 \times 10^{-8}$ & {$[3]$} \\
EDFA & $\mathrm{U}_{\text {EDFA }}$ & $4 \times 10^{-7}$ & {$[2]$} \\
Circulator & $\mathrm{U}_{\mathrm{Cir}}$ & $2 \times 10^{-7}$ & {$[2]$} \\
Optical Switch & $\mathrm{U}_{\mathrm{OS}}$ & $4 \times 10^{-7}$ & {$[2]$} \\
AWG & $\mathrm{U}_{\text {AWG }}$ & $4.8 \times 10^{-6}$ & {$[2]$} \\
CWDM & $\mathrm{U}_{\mathrm{CWDM}}$ & $1.44 \times 10^{-5}$ & {$[6]$} \\
FBG & $\mathrm{U}_{\mathrm{FBG}}$ & $10^{-7}$ & {$[5]$} \\
Splitter & $\mathrm{U}_{\mathrm{Spl}}$ & $4 \times 10^{-8}$ & {$[2]$} \\
Fiber & $\mathrm{U}_{\mathrm{F}}$ & $2.4 \times 10^{-7} / \mathrm{km}$ & {$[2]$} \\
\hline
\end{tabular}

As is illustrated in the above calculation and analysis, A is a constant. It means that the link reliability of the network is not affected by the scale of the network.

\subsection{Performance comparison}

To show the performance of proposed scheme, its characteristics is compared with them of existing schemes(shown in Table 5).

Table 5 Performance comparison results

\begin{tabular}{cccccc}
\hline & $\begin{array}{c}\text { Star } \\
\text { scheme }\end{array}$ & $\begin{array}{c}\text { Ring } \\
\text { scheme }\end{array}$ & $\begin{array}{c}\text { Grid } \\
\text { scheme }\end{array}$ & $\begin{array}{c}\text { Three- } \\
\text { dimensional } \\
\text { grid scheme }\end{array}$ & $\begin{array}{c}\text { The } \\
\text { proposed } \\
\text { scheme }\end{array}$ \\
\hline $\begin{array}{c}\text { Signal } \\
\text { blocking } \\
\text { Link }\end{array}$ & Large & -- & Large & Small & Small \\
$\begin{array}{c}\begin{array}{c}\text { flexibility } \\
\text { Network } \\
\text { reliability }\end{array} \\
\text { No }\end{array}$ & Weak & Wo & No & Yes & Yes \\
\hline
\end{tabular}


Here, in the star scheme ${ }^{[7]}$, the direct communication between ONUs is realized through a virtual ring. Direct communication signals need to be transmitted back to the RN for rescheduling. It will inevitably cause signal congestion and delay. Furthermore, the transmission link of the direct communication signal is not flexible. If the first $\mathrm{ONU}$ on the virtual ring wants to communicate directly with the last ONU, the transmission link must cover all ONUs between them. So, the direct communication signal received by the receiver of the target ONU will have more noise and lower power. In addition, the protection link lacks flexibility and the reliability of the network is poor.

In the ring scheme ${ }^{[8]}$, a dedicated ring optical link is established to support direct communication between ONUs. Compared with virtual ring in star network, CapEx of the network is higher due to the actual ring optical link. In the ring optical link, the communication between adjacent ONUs is extremely dependent. So, link of direct communication signal lose flexibility. In addition, the protection link is also inflexible. The network will not be able to resume normal when multi-point fiber failure happens. So, the reliability of the network is poor.

Different from the previous two schemes realizing direct communication between ONUs in a specific order, the grid scheme ${ }^{[9]}$ can realize direct communication between any two ONUs. However, direct communication signal between ONUs must be rescheduled in RN. Delay and signal congestion also occur in communication. In protection mode, the link of direct communication lacks flexibility. In the three-dimensional grid scheme ${ }^{[10]}$, direct communication between ONUs can be realized at ONU. Link of direct communication is flexible. The protection mechanism of the network is based on the ring protection mechanism. So, the network can't resist multi-point fiber failure. Furthermore, the direct communication between ONUs is half-duplex.

The scheme proposed in this paper is also based on grid topology. However, FDDC between any two ONUs can be realized at ONU. The direct communication link is further shortened, the possibility of signal blocking is greatly reduced and the transmission efficiency of direct communication is greatly improved. Furthermore, the link selection of direct communication is very flexible. The network can choose other alternative links for direct communication when signal congestion occurs in communication link. Moreover, three protection modes can resist all possible fiber failure, the reliability of the network is better.

In summary, the proposed scheme has significant advantages in many aspects, such as signal blocking, link flexibility, network reliability and so on.

\subsection{Simulation analysis of transmission performance}

\subsubsection{Simulation settings}

In order to further demonstrate the feasibility of the proposed architecture, a simulation based on OptiSystem 7.0 (Optiwave, Ottawa, Canada) was carried out. The simulation setting includes one $\mathrm{CO}$, one RN and eight ONUs. Under the condition of both normal mode and protection mode, the simulations of downlink communication and FDDC are realized respectively. The frequencies of downlink signals are $193.1 \mathrm{THz} 193.8 \mathrm{THz}$, while the frequencies of FDDC signals are 194.5THz $195.2 \mathrm{THz}$, the interval of wavelengths is $0.1 \mathrm{THz}$. For group $1\left(\mathrm{ONU}_{1}{ }^{1} \mathrm{ONU}_{1}{ }^{4}\right)$, $10 \mathrm{Gbit} / \mathrm{s} 2^{7}-1$ pseudo-random bit sequence (PRBS) is used to simulate downlink signals, while for group $2\left(\mathrm{ONU}_{2}{ }^{1} \sim \mathrm{ONU}_{2}^{4}\right), 5 \mathrm{Gbit} / \mathrm{s} 2^{7}-1$ PRBS is used to simulate downlink signals. All downlink signals are modulated in non-return to zero (NRZ) mode. The uplink signal is transmitted at the speed of $2.5 \mathrm{Gbit} / \mathrm{s}$ using NRZ data. FDDC signals are simulated by PRBS of 10Gbit/s in NRZ mode. In $\mathrm{CO}$, gain of EDFA is set at $30 \mathrm{~dB}$. The length of FF between $\mathrm{CO}$ and $\mathrm{RN}$ is set to $5 \mathrm{~km}$, the length 
of DF between RN and ONU is set to $1 \mathrm{~km}$, and the length of the interconnected fiber between ONU is set to $0.5 \mathrm{~km}$.

\subsubsection{BER curve}

Here, the transmission principles of ONU's downlink signals are the same. Now, take $\mathrm{ONU}_{1}{ }^{1}$ and $\mathrm{ONU}_{2}{ }^{1}$ as examples to explain the performance of downlink signals. BER curves of downlink signals in normal and protection modes are shown in Fig.12. The relationship between BER and optical received power is: the value of BER decreases as the received power increases. It can be seen from the figure that the signal performance of $\mathrm{ONU}_{2}{ }^{1}$ is better than that of $\mathrm{ONU}_{1}{ }^{1}$ in normal mode. The signal transmission rates of $\mathrm{ONU}_{2}{ }^{1}$ and $\mathrm{ONU}_{1}{ }^{1}$ are $5 \mathrm{Gbit} / \mathrm{s}$ and $10 \mathrm{Gbit} / \mathrm{s}$ respectively. The above results can further confirm the principle: under the same conditions, the faster signal transmission rate is, the higher BER of signal will be. In Fig.12, BER of $\mathrm{ONU}_{1}{ }^{1}$ in protection mode is higher than that in normal mode. In protection mode, the signal transmitted to $\mathrm{ONU}_{1}{ }^{1}$ must pass through $\mathrm{ONU}_{1}{ }^{\mathrm{n}}$. So, the BER is higher and the signal transmission performance is poor by the reasons of passing through more optical devices and having more noise. In addition, it can be seen that BER of downlink signal is less than $10^{-9}$. This confirms that the proposed network meets the requirement of communication standard.

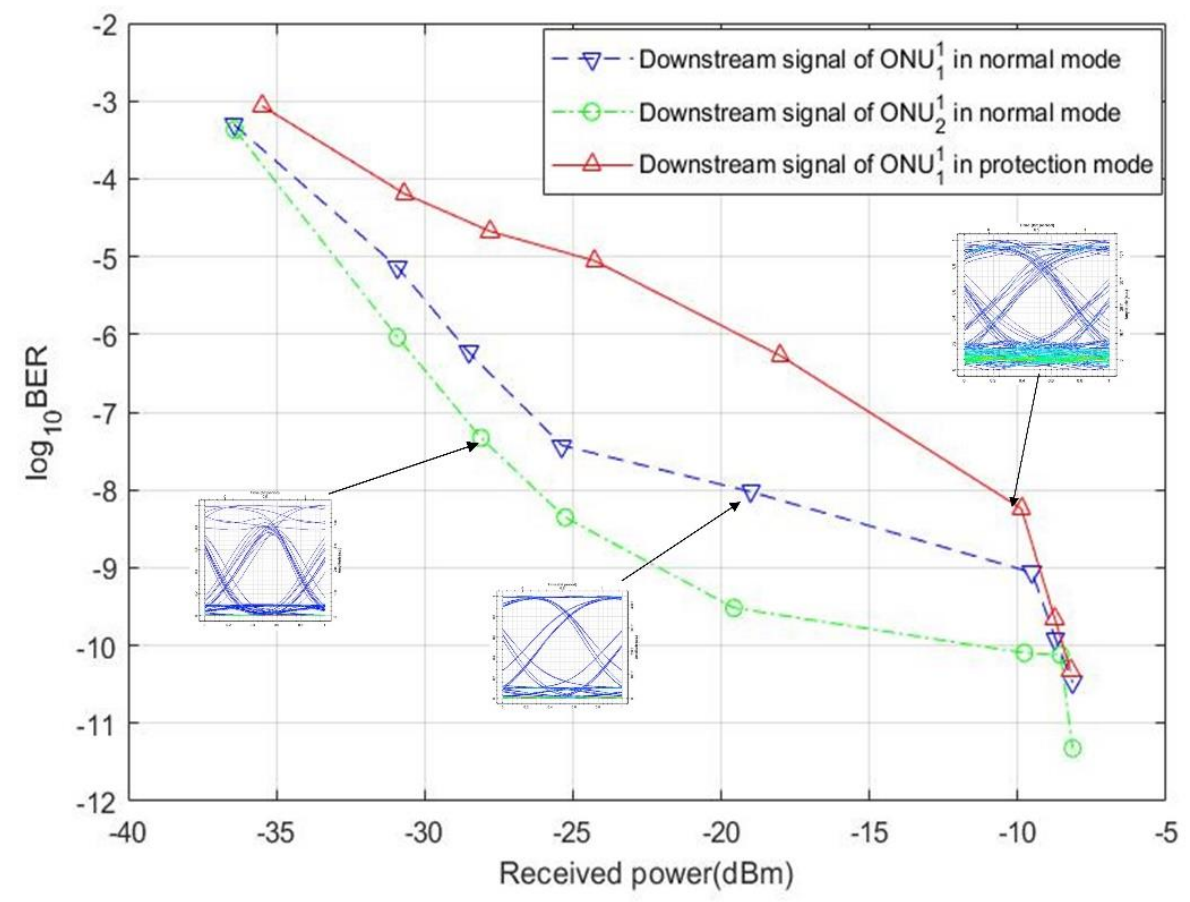

Fig.12. BER curves of downlink signals in normal and protection mode

The BER curves of FDDC In normal and protection modes are shown in Fig.13. Similarly, the BER of all signals decreases as the received power increases. It can be seen from the figure that the BER curves of $\left(\mathrm{ONU}_{1}{ }^{2}\right.$-to- $\left.-\mathrm{ONU}_{1}{ }^{4}\right)$ and $\left(\mathrm{ONU}_{1}{ }^{4}\right.$-to-ONU $\left.{ }_{1}^{2}\right)$ are very close. This is because FDDC links between $\mathrm{ONU}_{1}{ }^{2}$ and $\mathrm{ONU}_{1}{ }^{4}$ are the same one. Similarly, the BER curves of $\left(\mathrm{ONU}_{1}{ }^{1}\right.$-to-ONU $\left.{ }^{2}\right)$ and $\left(\mathrm{ONU}_{2}{ }^{2}\right.$-to-ONU $\left.{ }_{1}^{1}\right)$ almost coincide. $\mathrm{ONU}_{1}{ }^{1}$ and $\mathrm{ONU}_{2}{ }^{2}$ are in different groups. BER of communication link between ONUs in different groups is poorer than that in one group because the former one has longer transmission link. Furthermore, when the network happens to failure, the FDDC link of $\left(\mathrm{ONU}_{1}{ }^{2}\right.$-to-ONU $\left.{ }_{1}^{4}\right)$ becomes longer, and the relative BER becomes poorer. Although 
the links of $\left(\mathrm{ONU}_{1}{ }^{1}\right.$-to-ONU $\left.{ }_{2}^{2}\right)$ in normal mode and $\left(\mathrm{ONU}_{1}{ }^{2}\right.$-to- $\left.\mathrm{ONU}_{1}{ }^{4}\right)$ in protection mode are different, the number of optical devices and length of optical fiber related to the link are similar. So, BER curves of $\left(\mathrm{ONU}_{1}{ }^{1}\right.$-to-ONU $\left.{ }_{2}^{2}\right)$ in normal mode and $\left(\mathrm{ONU}_{1}{ }^{2}\right.$-to-ONU $\left.{ }_{1}^{4}\right)$ in protection mode are very close. Compared with Fig.12, the transmission performance of FDDC signal is better, and the BER of FDDC signal is less than $10^{-16}$. This confirms that the proposed network meets the requirement of communication standard.

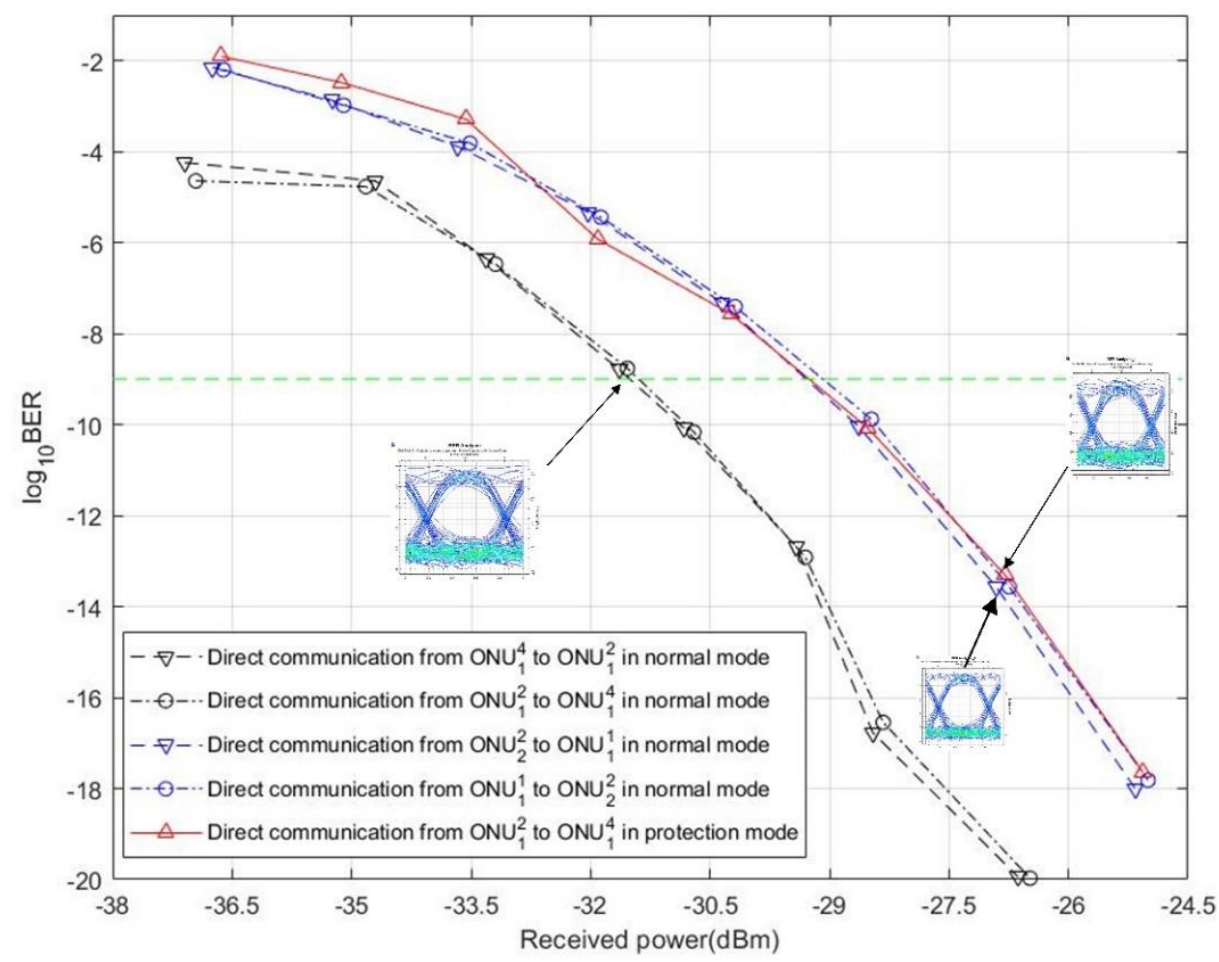

Fig.13. BER curves of FDDC signals in normal and protection mode

\section{Conclusion}

A novel architecture with full-duplex communications between any two ONUs for optical access network has been completed in this paper. At first, a CS is constructed to finish the architecture and further realize full-duplex communications between any two ONUs among WDM-PONs. Next, interconnected optical fibers between ONUs are utilized to provide protection for communications between ONUs so as to achieve three-level protections (feeder optical fiber protection, distributed optical fiber protection and interconnected optical fiber protection) in optical access network. The network reliability is greatly elevated to fully meet the operator's 5 ' 9 ' requirements. Furthermore, an EM is designed to tremendously reduce the Capex and Opex of network, and flexibly expand and optimize the network. The scale of network can be normally up to 768 users. Finally, the simulation and analysis demonstrates the effectiveness of the proposed architecture.

\section{Acknowledgement}

Supported by 111 Project (D20031)

This work was supported by 111 Project (No. D20031). 


\section{References}

[1]. X. Li, C. Gan, K. Gou, and Y. Zhang, "A novel WDM-MAN enabling cross-regional reconfiguration and comprehensive protection based on tangent-ring," Optics Communications, 430: 416-427, 2019.

[2]. X. Li, C. Gan, Z. Liu, H. Qiao, and Y. Yan. Resilient intersection-ring architecture featuring online expansion and intersectional mutual protection.IEEE/OSA Journal of Optical Communications and Networking.2018, 10(6): 613-623

[3]. S. Zhang, W. Ji, X. Li, K. Huang, and Z. Yan. Efficient and reliable protection mechanism in long-reach PON.IEEE/OSA Journal of Optical Communications \& Networking.2016, 8(1): 23-32

[4]. C.Feng, C. Gan, S. Guo, Z. Gao, W. Li, and Y. Fang. A Novel Modularized Twin-Ring Wavelength-Division Multiplexer Access Network with Fiber-Fault Protection and Wavelength Tetra-Reuse.Fiber \& Integrated Optics.2015, 34(3): 112-130

[5]. J.Chen, L.Wosinska, M.Niaz Chughtai, and M.Forzati.ScalablePassiveOptical Network Architecture for Reliable Service Delivery. Journal of Optical Communication Network.2011, 3(9):677-673

[6]. X. Li, C. Gan, K. Gou, and Y. Zhang. A novel WDM-MAN enabling cross-regional reconfiguration and comprehensive protection based on tangent-ring. Optics Communications.2019, 430: 416-427

[7]. Y. Zhou, C. Gan, B. Chen, and X. Ma. An upgradeable WDM-PON for broadcast and LAN services.Optical and Quantum Electronics.2010, 42(3): 157-163

[8]. X. Li, C. Gan, Z. Liu, and J. Hua. The Analysis of Network Scale and Reliability in Ring-and-Tree-Based Metro-Access Network with LAN Service. Fiber \& Integrated Optics, 2017, 36: 203-217D. Monoyios, A. Hadjiantonis, K. Vlachos, G. Ellinas. Efficient inter-ONU communication in ring-based WDM-PONs.16th International Conference on Transparent Optical Networks (ICTON2014). July 6-10,2014, inGraz, Austria.ICTON2014, pp: 1-4

[9]. X. Li, C. Gan, Y. Yan, et al. Grid architecture of a metro-access optical network to support discretionary peer-to-peer intracommunication and intercommunication between ONUs. IEEE/OSA Journal of Optical Communications and Networking, 2019, 11(3): 130-139

[10]. W. Lin, C.Gan*, Y.Chen, Y.Guo and N.Zhan. Three-dimensional grid architecture supporting discretionary direct communications among optical network units in metro-access networks. IEEE/OSA Journal of Optical Communications and Networking, 2019, 11(12): 613-623

[11]. A Flexible Remote Node Architecture for Energy Efficient Direct ONU Internetworking in TDM PON 2017 International Conference on Computer, Communications and Electronics (Comptelix) Manipal University Jaipur, Malaviya National Institute of Technology Jaipur \& IRISWORLD, July 01-02, 2017

[12]. Zhang S, Ji W, Li X, et al. Efficient and Reliable Protection Mechanism in Long-Reach PON. IEEE/OSA Journal of Optical Communications \& Networking, 2016, 8(1): 23-32. 
Figures

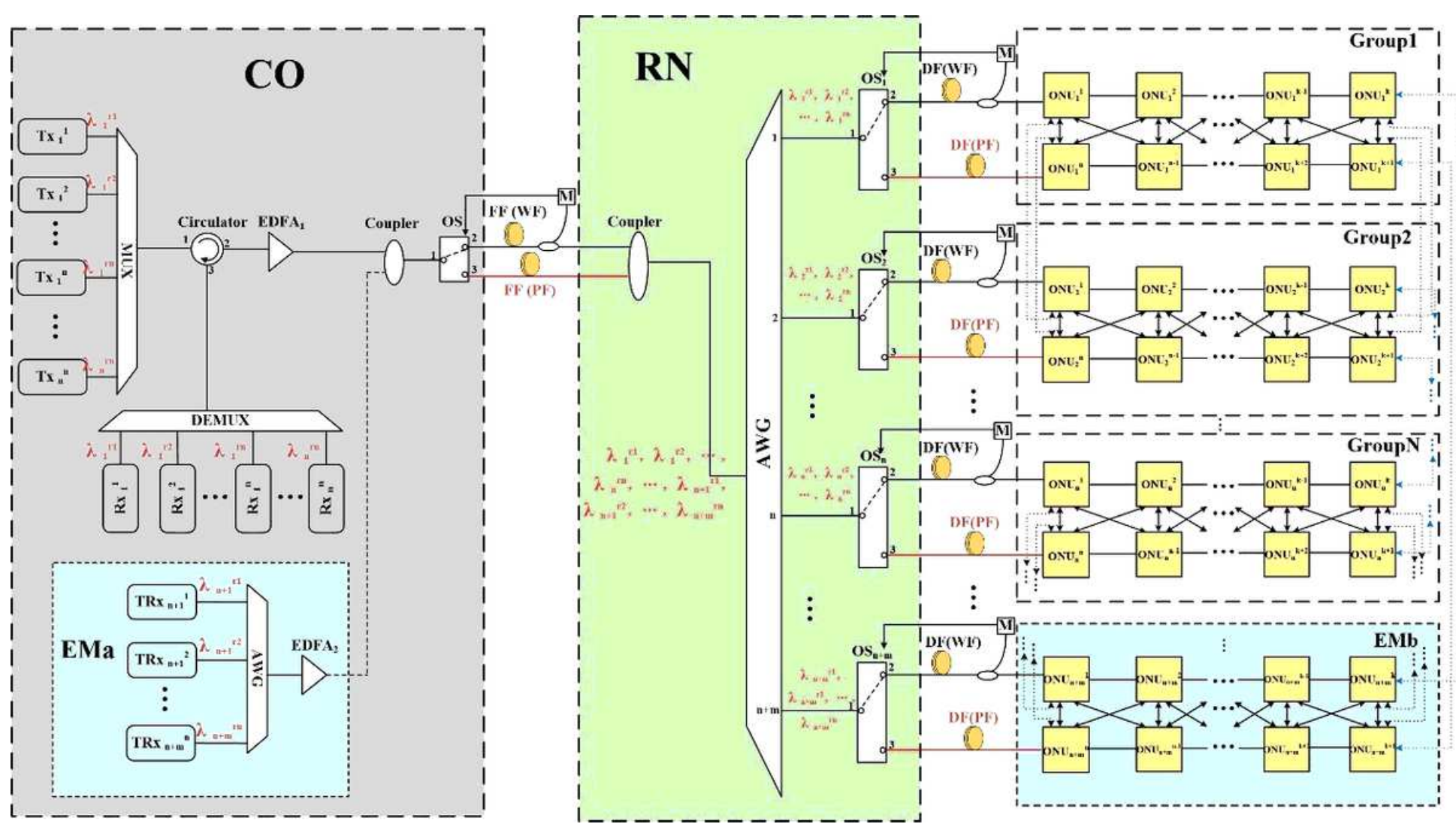

Figure 1

Network architecture with FDDC between ONUs 


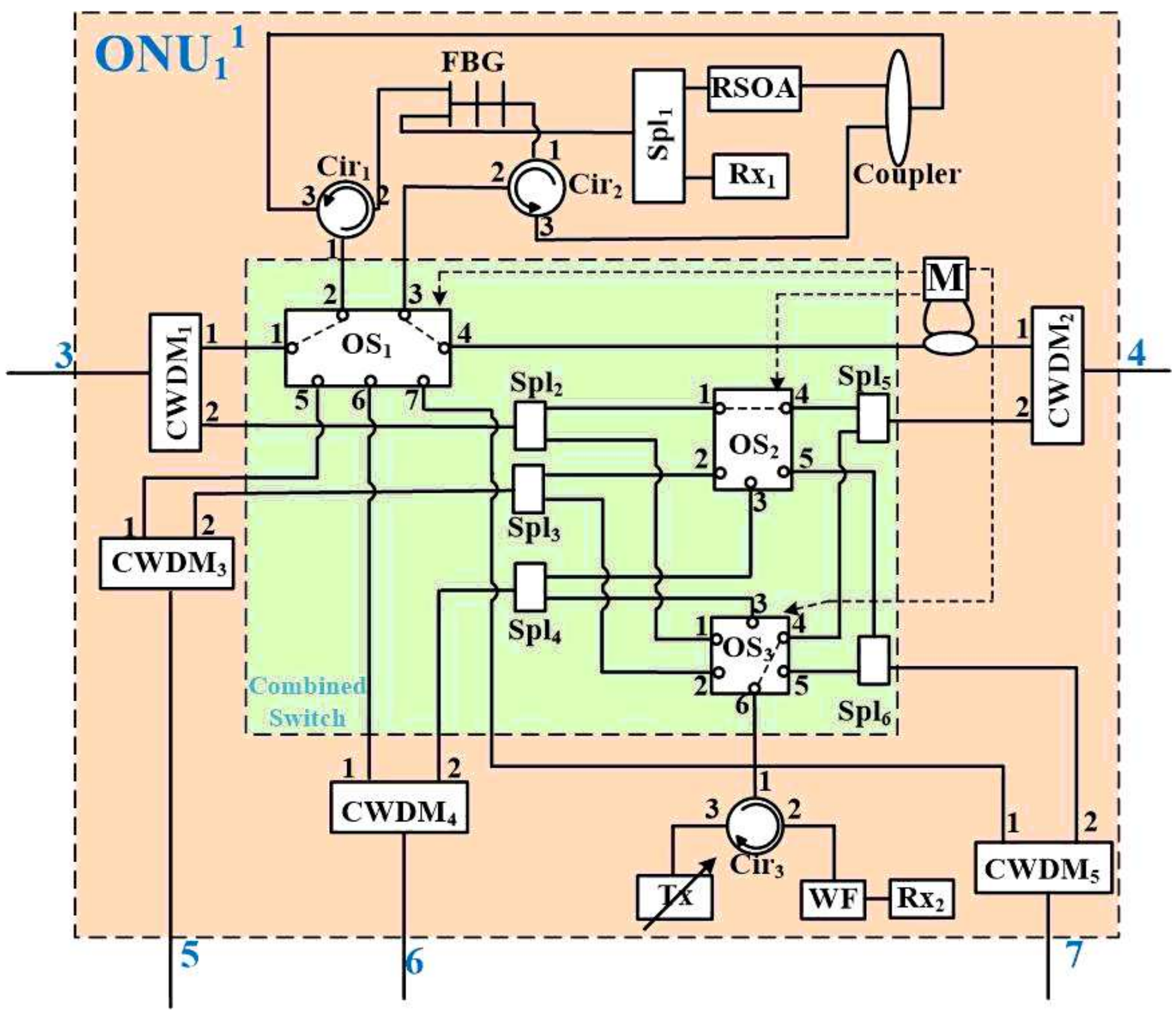

Figure 2

The structure of ONU

$\dashv$ FSR $\rightarrow-$ FSR $\rightarrow|\cdots| \longleftarrow$ FSR $\rightarrow \mid$

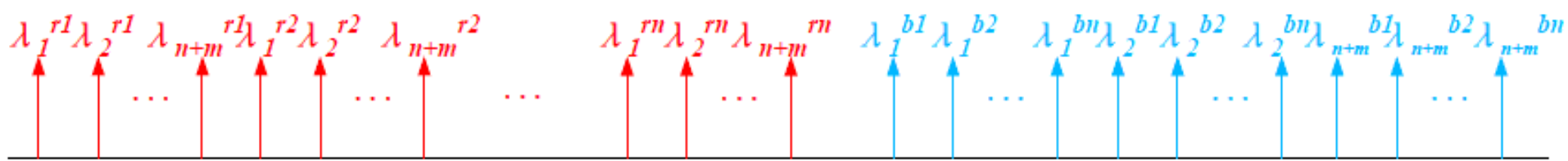

$\longmapsto$ Red Band $\longrightarrow \mid \longmapsto$

Figure 3 
Wavelength allocation scheme

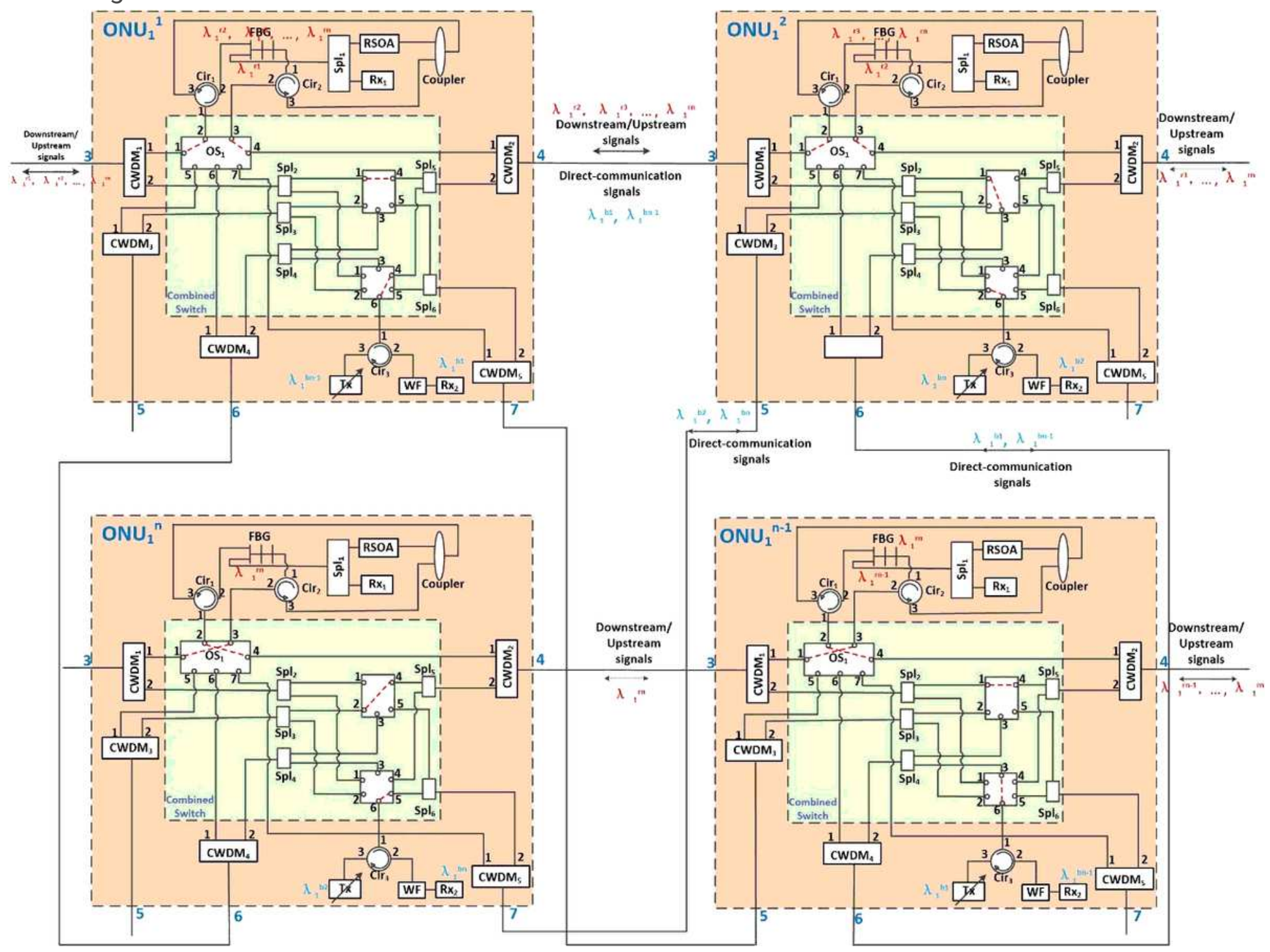

Figure 4

Normal working mode

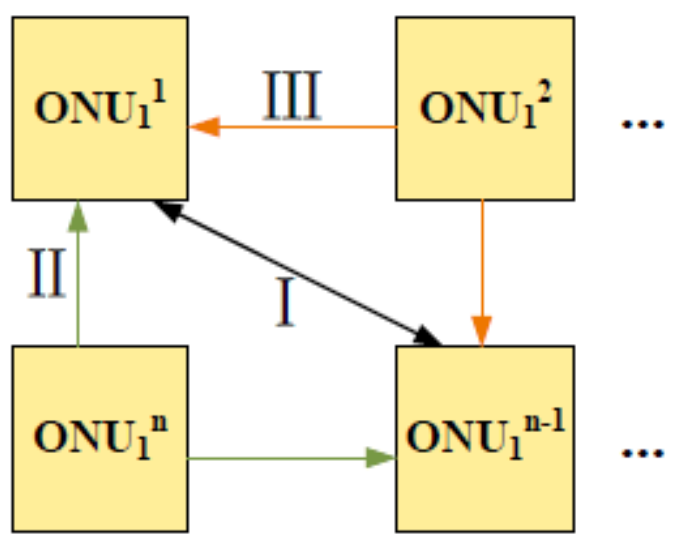

Figure 5 


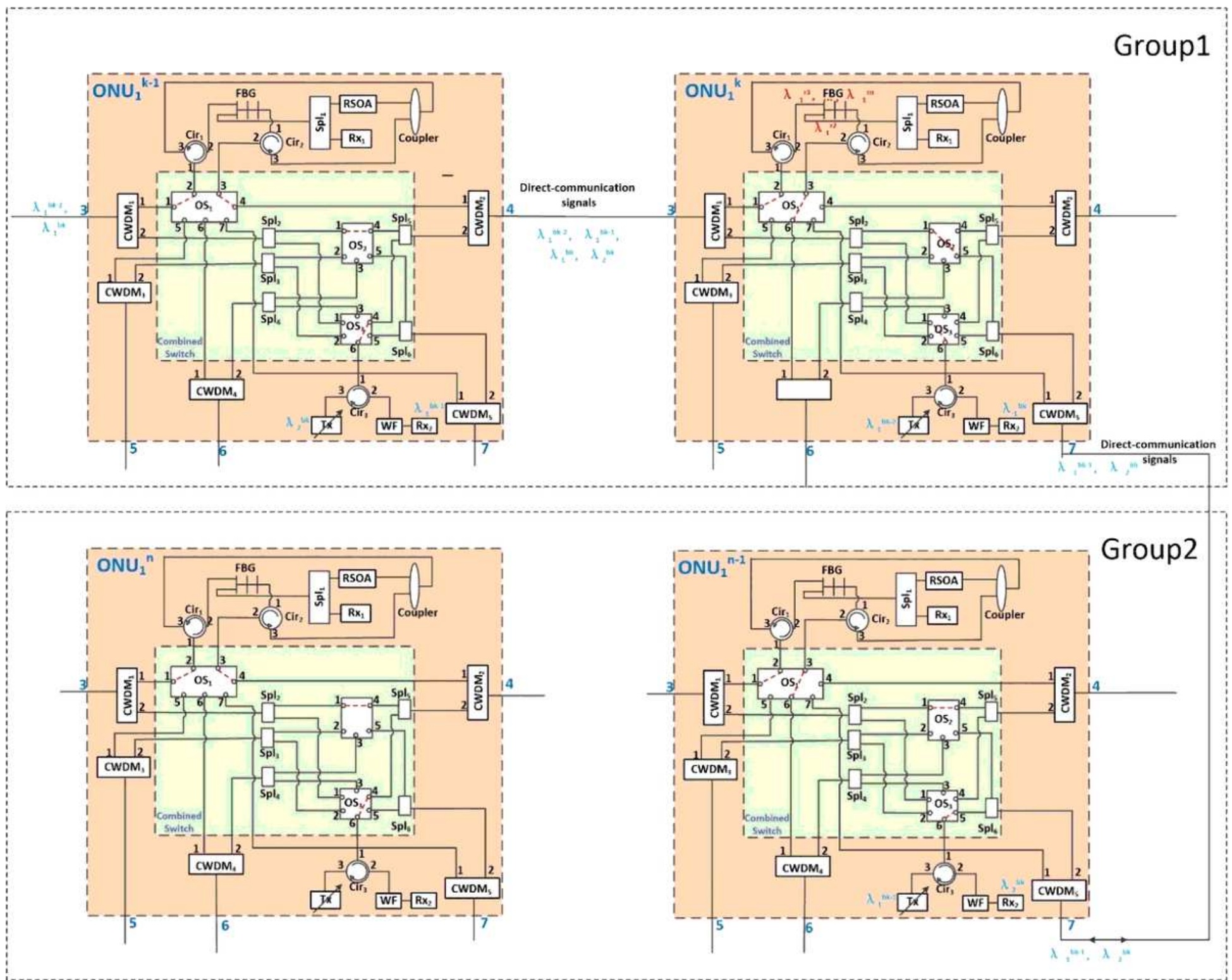

Figure 6

Communication between groups 


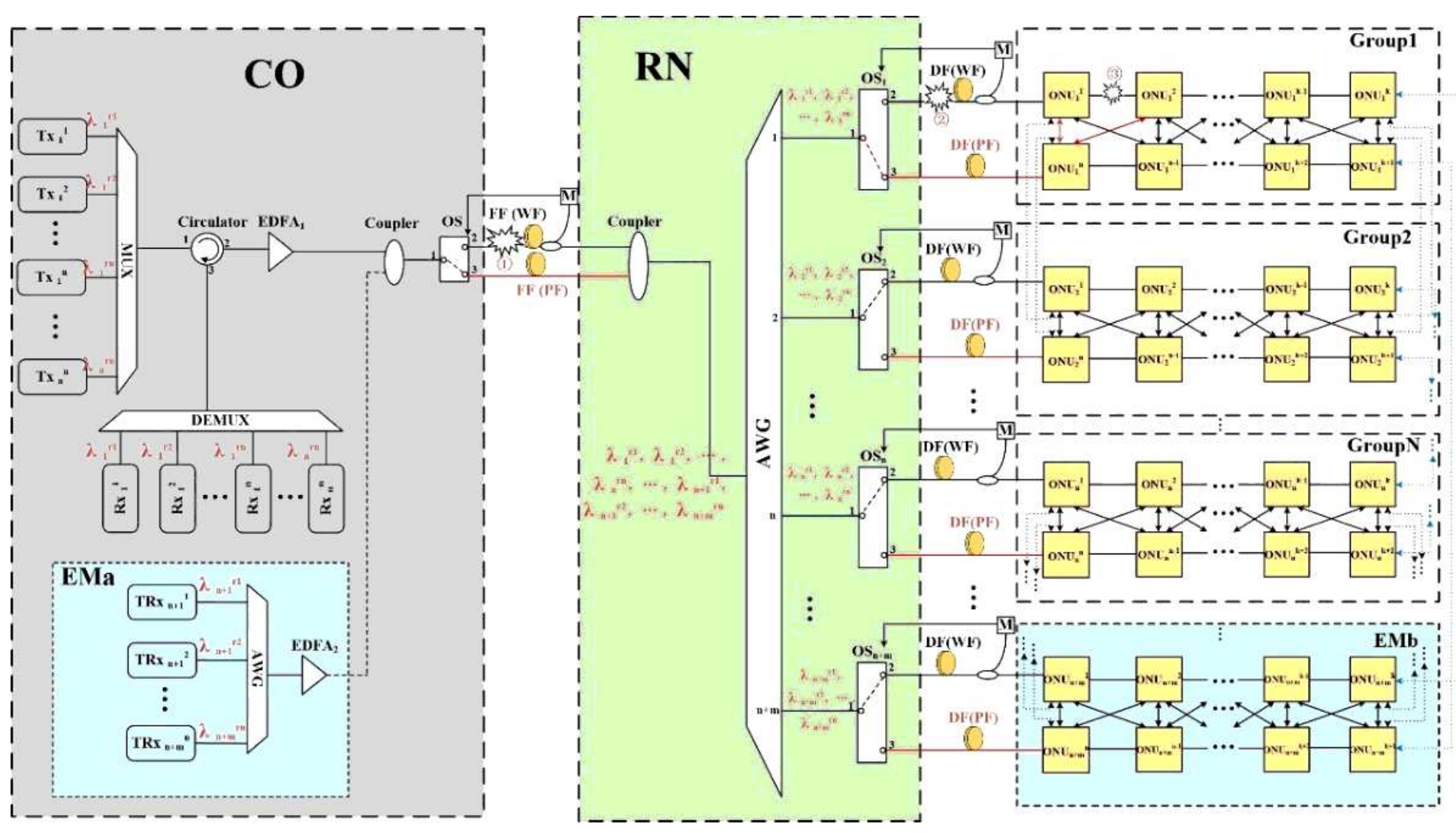

Figure 7

Protection Mode 1 


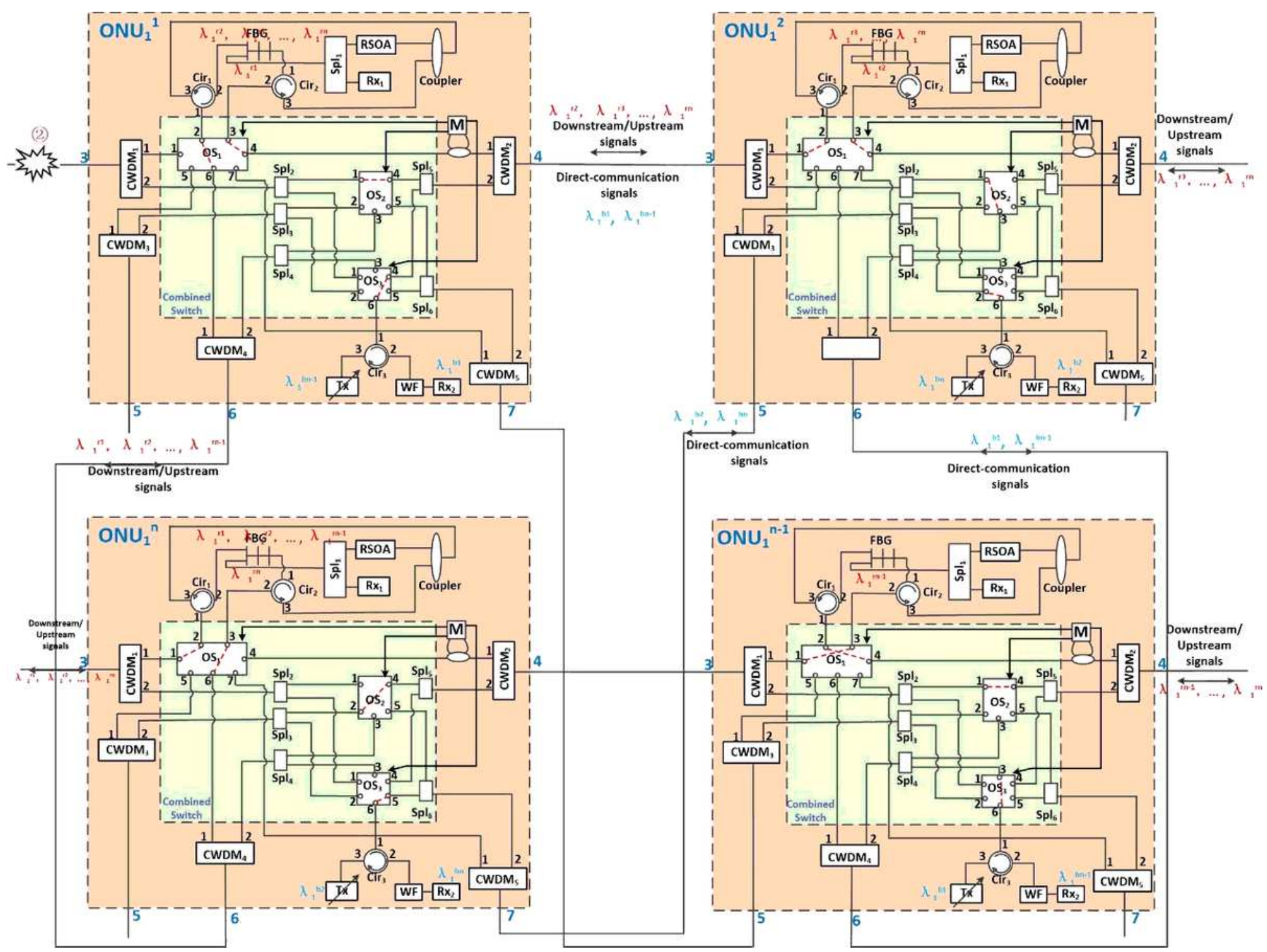

Figure 8

Protection Mode 2 


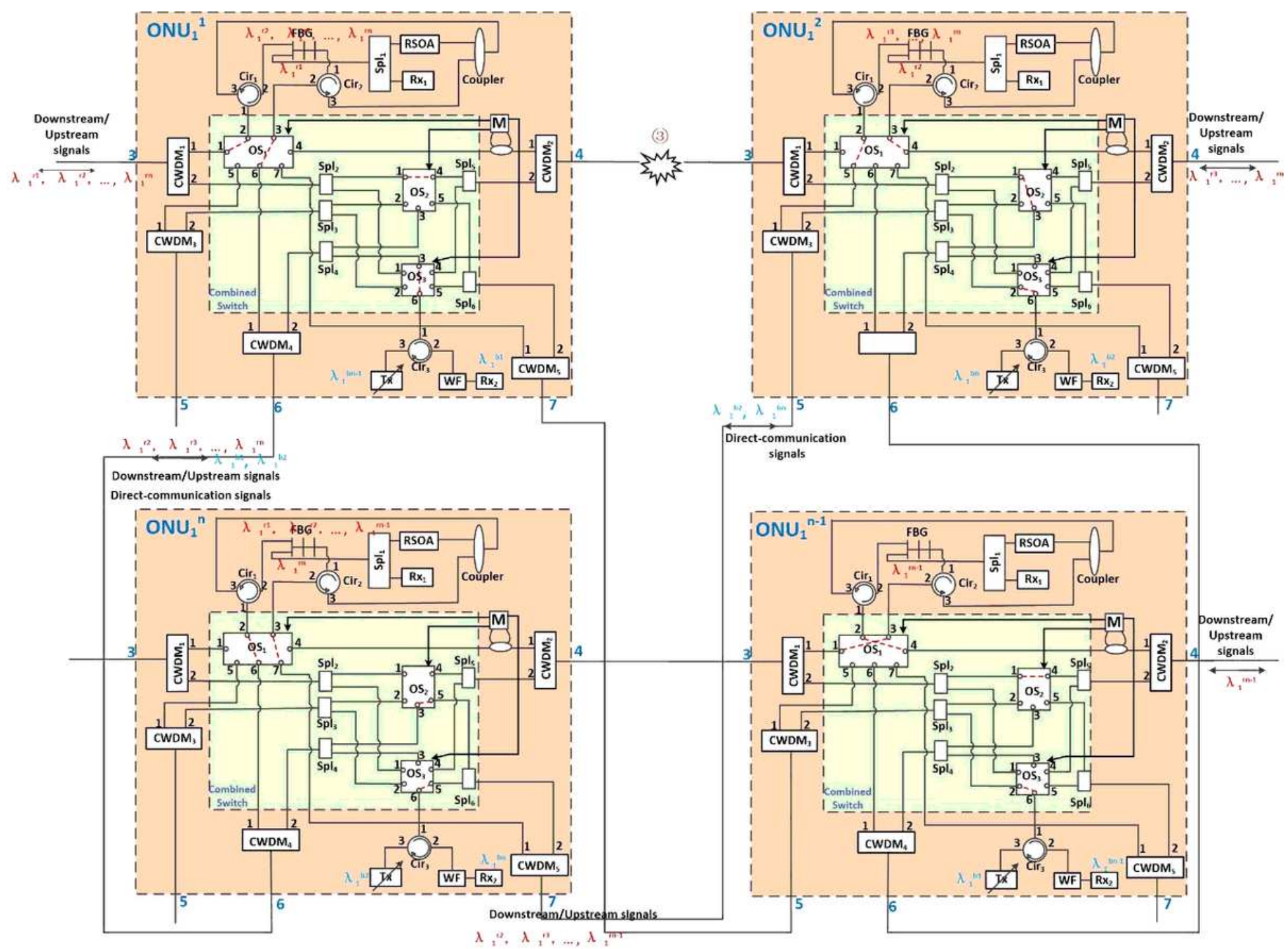

Figure 9

Protection Mode 3 


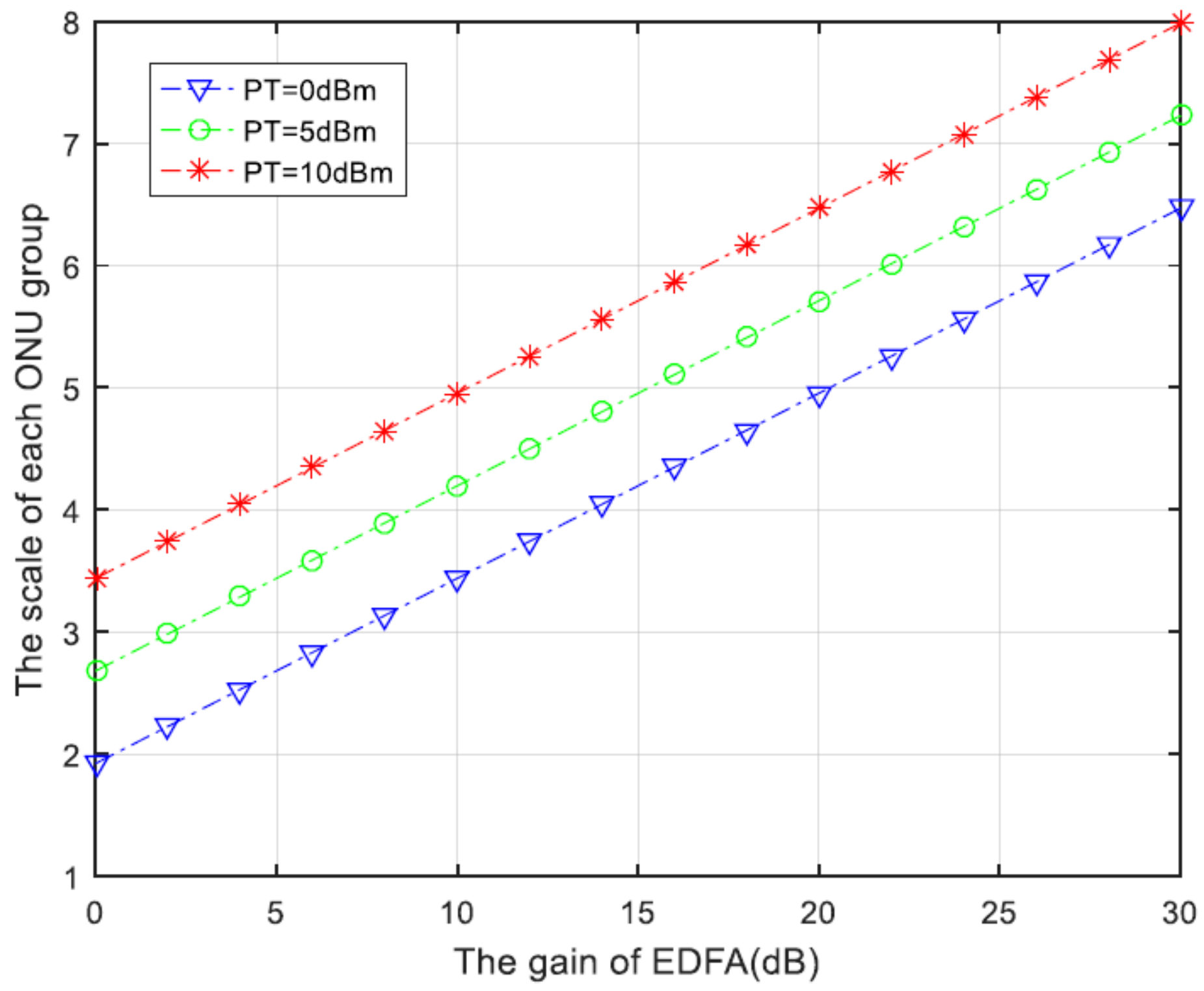

Figure 10

The relationship between $\mathrm{G}$ and $\mathrm{n}$ when $\mathrm{PT}$ is a fixed value 


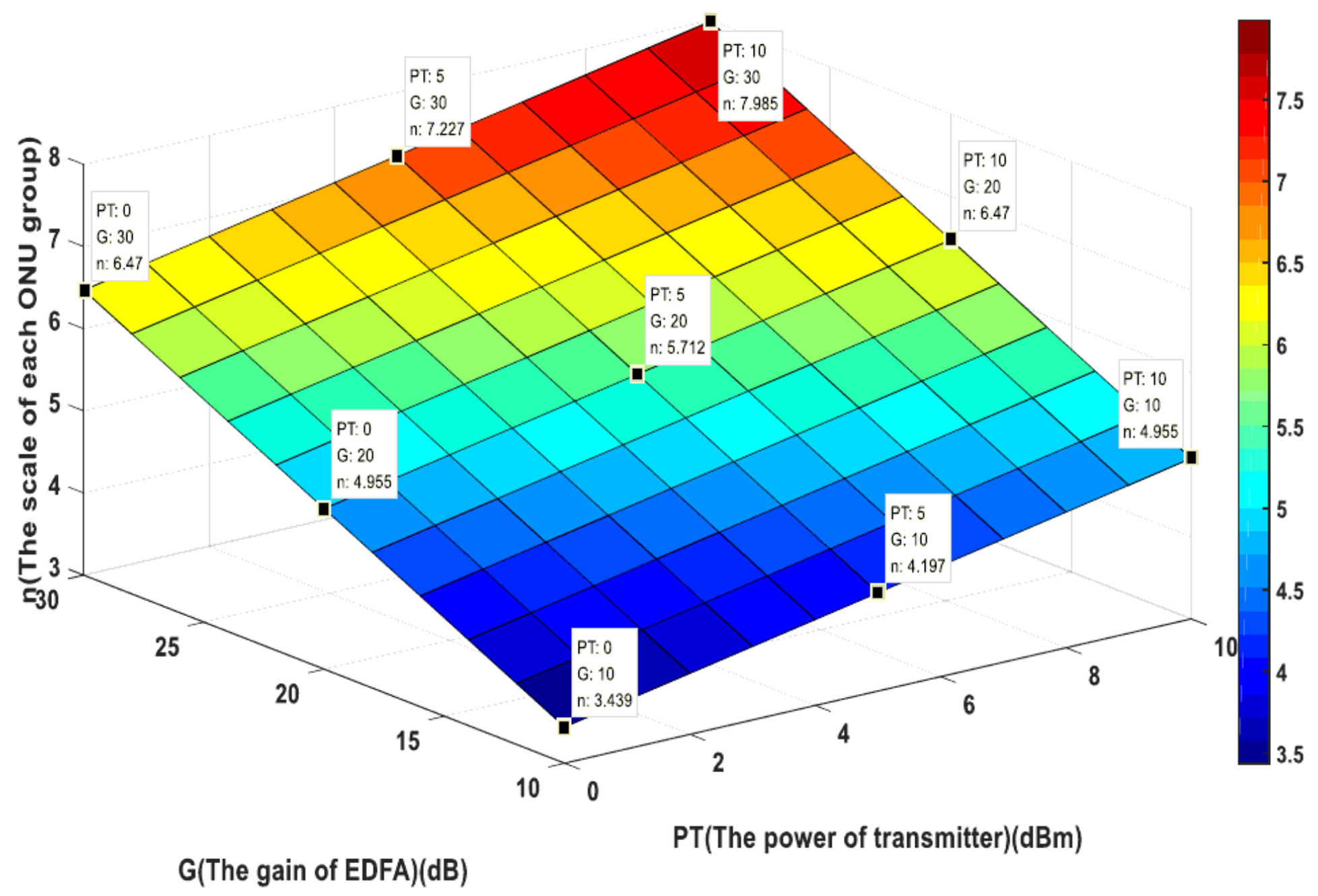

Figure 11

The relationship between $\mathrm{PT}, \mathrm{G}$ and $\mathrm{n}$ 


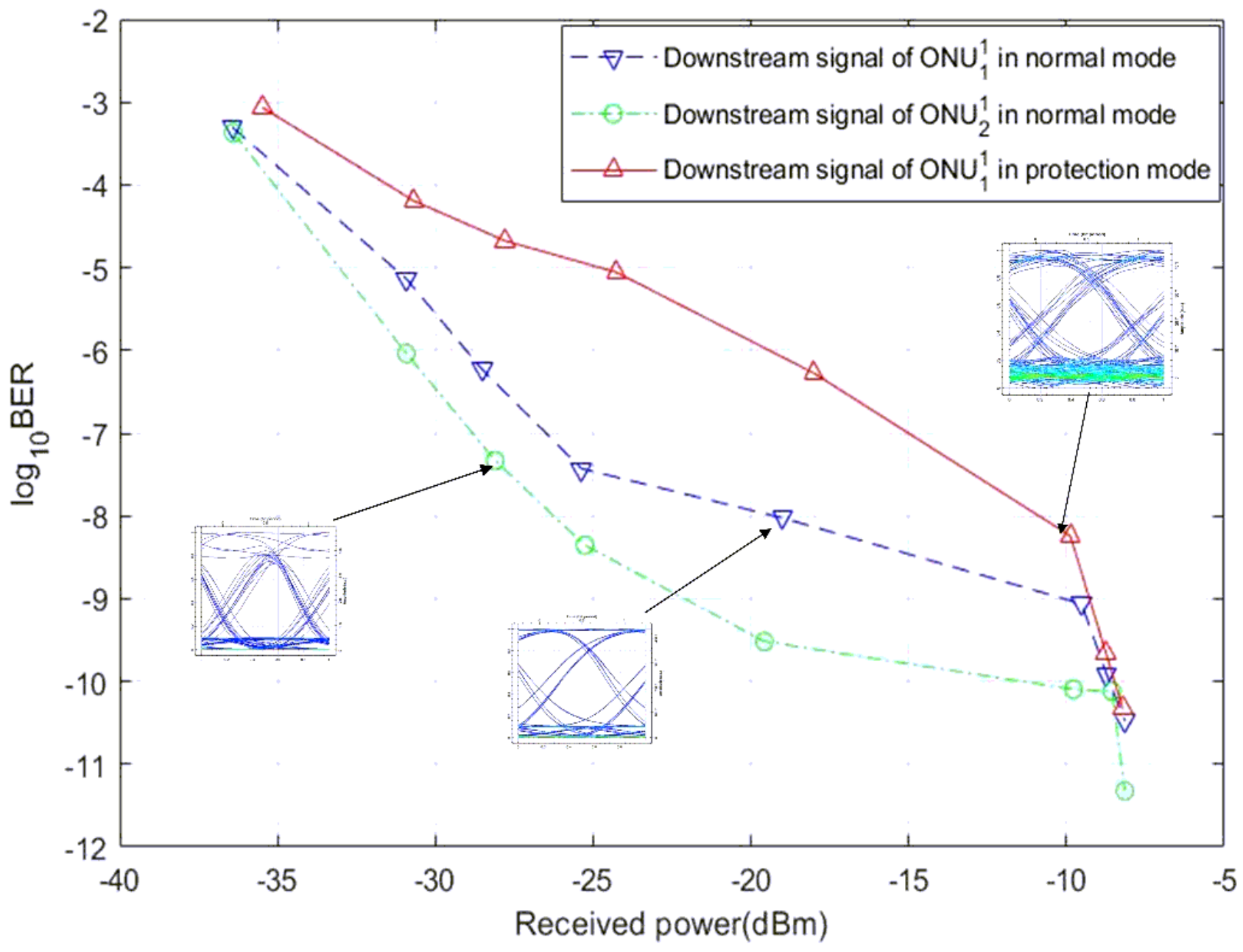

Figure 12

BER curves of downlink signals in normal and protection mode 


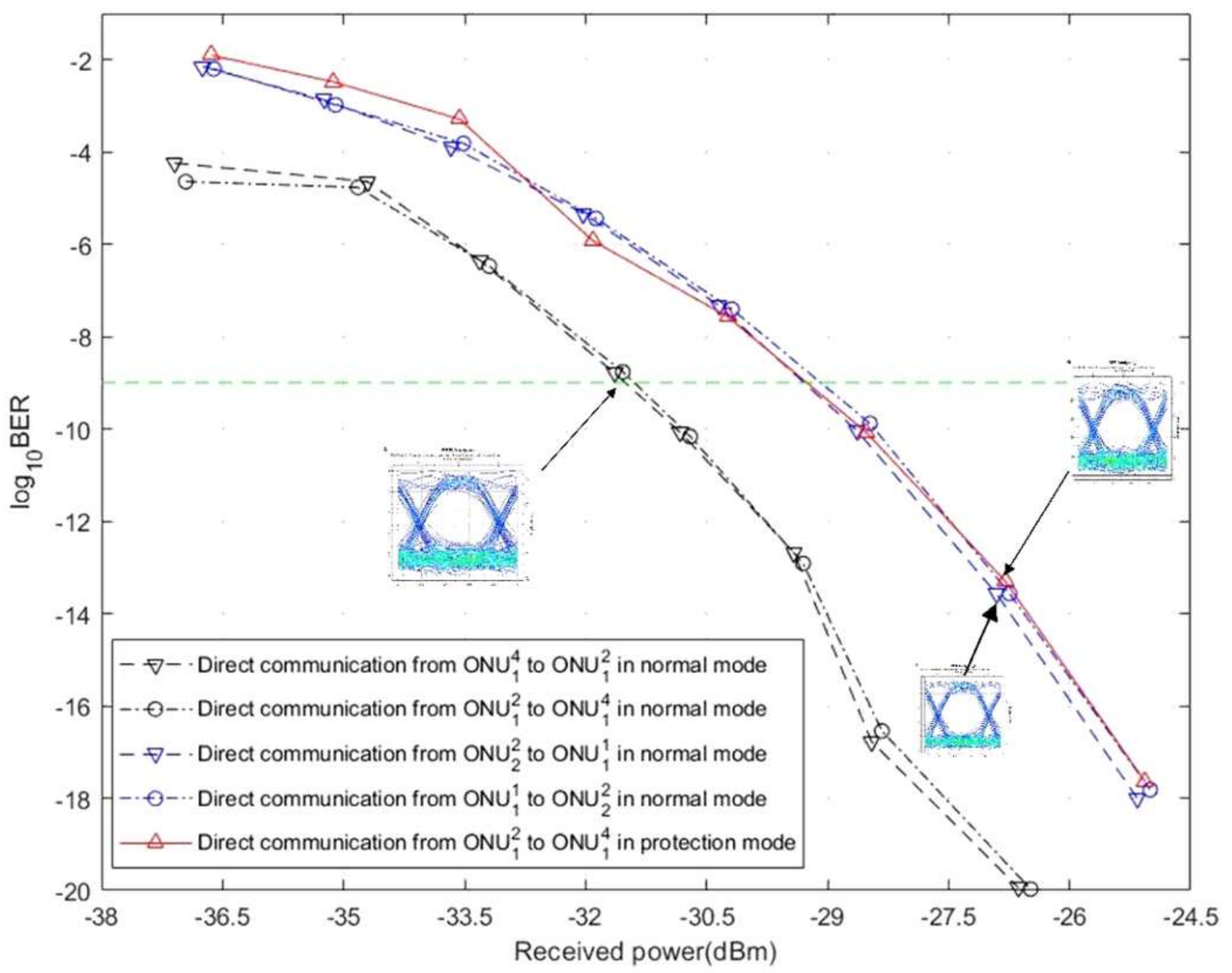

Figure 13

BER curves of FDDC signals in normal and protection mode 